\title{
EL REGADÍO EN MAGALLÓN (ZARAGOZA) HASTA EL SIGLO XV Y LA DOCUMENTACIÓN MEDIEVAL SOBRE AGUA CONSERVADA EN SU ARCHIVO MUNICIPAL Y SINDICATO DE RIEGOS
}

\author{
IRRIGATION IN MAGALLÓN (ZARAGOZA, SPAIN) UNTIL 15th CENTURY \\ AND MEDIEVAL DOCUMENTATION ABOUT WATER CONSERVED \\ IN ITS TOWN HALL AND ITS IRRIGATORS' ASSOCIATION
}

Francisco Saulo Rodríguez Lajusticia

Universidad de Cantabria

\begin{abstract}
Resumen: Magallón es un municipio de aproximadamente 1200 habitantes, situado en la actual comarca de Campo de Borja. Con evidencias de irrigación en la zona desde época romana, a partir de la Reconquista el regadío pasó progresivamente de manos musulmanas a cristianas. Los aspectos derivados de este tema, la conflictividad surgida por los recursos hídricos en el seno de la competencia con las demás poblaciones del valle medio del río Huecha y la rica, abundante e inédita documentación en pergamino que se conserva en el Archivo Municipal y en el Sindicato de Riegos de esta localidad son los temas que centran la atención en este artículo.
\end{abstract}

Palabras clave: Regadío, Magallón (Zaragoza), conflictividad, turnos, Aragón.
Abstract: Magallon is a town with 1,200 inhabitants approximately, located in the Aragonese region known as "Campo de Borja”. With some evidences of irrigation in this land since Roman times, after the Christian conquist, water management went from Muslims to Chistians. The topics according this theme, the conflicts originated by water resources within the competition between Magallón and other populations in the river Huecha valley and the very detailed and unpublished documents which are preserved in the Municipal Archive and in the Irrigators' Association in this town are the main issues that focus on this report.

Keywords: Irrigation, Magallón (Zaragoza), conflict, turns, Aragón. 
A la eterna memoria de Jesús Maiso González, buen conocedor del Campo de Borja y del monasterio de Veruela

\section{Breve estado de la cuestión}

La bibliografía sobre el regadío medieval hispano es tan numerosa que resulta prácticamente imposible abordarla en un artículo de estas características, siendo necesario para poder hacerlo un estudio específico únicamente centrado en la elaboración de un estado de la cuestión sobre el tema. En todo caso, sirva como muestra de la plena actualidad que sigue teniendo entre los medievalistas la aparición desde 2010 de diversos trabajos de gran interés y muy dignos de tener en cuenta. ${ }^{1}$

Centrándome directamente en la localidad zaragozana de Magallón, objeto de estudio en este artículo, y prescindiendo por el momento de referencias bibliográficas más específicas que se citarán más adelante, los ya clásicos estudios de Eusebio García o de Juan Bolea sobre los regadíos en lo que son las actuales comarcas de Tarazona y el Moncayo y Campo de Borja (García, 1960: 120-127 y Bolea, 1986: 436-466), ${ }^{2}$ así como los datos que facilitan las historias locales escritas sobre Magallón, Borja o Agón proporcionan un más que valioso punto de partida para informarse sobre el tema. ${ }^{3}$

1 Véanse, por ejemplo, Martínez, 2010; VV. AA., 2010; Madani, 2012 o Del Val y Bonachía, 2012.

El motivo por el cual mi estado de la cuestión abarca desde 2010 es porque, no hace mucho, publiqué un artículo sobre este tema en esta misma revista (Rodríguez, 2009), en el cual ya figura un estudio de las publicaciones hasta ese año inclusive. Por esta razón, y a fin de no caer en repeticiones innecesarias, los trabajos que cito en esta nota se refieren exclusivamente a algunas novedades aparecidas desde entonces y que me parecen especialmente interesantes.

En todo caso, reafirmo la validez del estado de la cuestión que realicé en 2009 y, en especial, de algunos trabajos imperecederos y absolutamente modélicos para este tipo de estudios, tales como el de Sesma, Utrilla y Laliena, 2001.

2 Es especialmente interesante en la primera de estas monografías un mapa sobre los regadíos del Huecha a Magallón ampliamente utilizado por historiadores posteriores, entre los que me incluyo.

3 A la espera de que se publique Sabio (en prensa), el estudio más completo hasta la fecha sobre esta localidad es Pardos, 1973 y, en especial, el capítulo tercero en el que se habla de la distribución del agua y de sus pleitos (pp. 39-58), si bien cuenta con un discurso bastante desordenado que entremezcla datos de diferentes épocas.Con respecto a las demás referencias, en Rújula y Lafoz, 1995: 84-101 hay un espacio generoso dedicado al regadío, si bien lo único que los autores mencionan sobre Magallón es una sentencia de 1446 sobre la que hablaré más adelante.

En cuanto al libro sobre Agón (Lajusticia, 2003), no cuenta con ninguna sección específica sobre el regadío, si bien contiene numerosas menciones al tema del agua en sus capítulos sobre la toponimia agonera, la granja de Muzalcoraz y la economía entre los siglos XII y XV (caps. II, XI y XV, respectivamente). 
En un segundo nivel de concreción, encontramos una bibliografía mucho más específica sobre el regadío en el valle del río Huecha, entre la que el mejor trabajo sin ninguna duda es el realizado por Guillermo Carranza. Así, este autor dedica sendos apartados a la acequia de Marbadón, a la sentencia arbitral de 1446 que regulaba el uso de sus aguas y a otros conflictos que, a lo largo del siglo XV y de la Edad Moderna, fueron surgiendo por este motivo en términos magalloneros (Carranza, 2009: 71-73 y 119-121).

No puede dejar de mencionarse tampoco la aportación que hizo a este tema Christopher Gerrard al tratar sobre el regadío medieval en el Huecha y de cómo el monasterio de Veruela introdujo elementos desestabilizadores en todo el sistema que provocaron una ruptura en el equilibrio de fuerzas entre los regantes (Gerrard, 2011). Por otra parte, en lo que se refiere a Magallón, lo cierto es que su artículo apenas contiene datos que no hubieran sido ya dichos por otros autores.

Mención aparte merece la bibliografía que tiene que ver con el monasterio cisterciense de Santa María de Veruela, institución que contó en la Edad Media con unas dependencias, la granja de Mazalcoraz, ${ }^{4}$ que estaba situada entre Magallón y Agón y contra la cual los magalloneros tuvieron numerosos pleitos a lo largo de toda su historia por la rivalidad que mantuvieron con los monjes por el uso del agua.

Así, Simonne Teixeira, al analizar el aprovechamiento que los conquistadores cristianos hicieron en el siglo XII de las infraestructuras preexistentes, estudió detenidamente el término de Magallón y sus sistemas hidráulicos de Marbadón, Lugar del Plano y Agua Baja, procediendo con ello a una metódica reconstrucción del espacio agrario magallonero en época medieval y ubicando con precisión los topónimos que aparecen en la documentación (Teixeira, 1995: 306-326).

Por último, la historia del regadío medieval de Magallón cuenta con un aporte propio publicado en esta misma revista en el que analicé los enfrentamientos que se produjeron entre la villa de Magallón y la granja de Mazalcoraz por cuestiones relacionadas con el riego (Rodríguez, 2009: 221-224), si bien tampoco puede considerarse un estudio completo sobre el tema si se tiene

Con respecto al nombre de esta granja verolense, que la mayoría de la bibliografía denomina «Muzalcoraz» en vez de «Mazalcoraz», ya tuve ocasión de explicar en mi tesis doctoral el motivo por el cual propongo que se utilice el nombre que yo empleo, por lo menos para época medieval: véase Rodríguez, 2010: 370 . 
en cuenta que únicamente abordé los siglos XIV y XV y tan sólo los aspectos del regadío magallonero que tenían relación con el monasterio de Veruela y su granja, quedando pendientes las centurias anteriores y todo aquello en lo que no estaba implicado el cenobio cisterciense.

\section{El origen del regadío en Magallón}

Es mucho lo que se ha escrito sobre el origen de los regadíos en España y sobre si éstos se deben más a los romanos o a los musulmanes, llegándose en ocasiones a discusiones sin término que no aclaran nada.

En este sentido, me parecen especialmente contundentes unas palabras de Miquel Barceló en las que resalta que no es tan importante saber si unas determinadas infraestructuras hidráulicas son de origen romano o islámico porque «saber esto es bien poca cosa si no va acompañado de otros conocimientos como, por ejemplo, el estado en que los árabes y beréberes las encontraron, las adiciones y modificaciones que hicieron, el sentido preciso de estos cambios, los objetivos diferentes o similares en la organización de la producción, la selección de los productos, la forma diferente o similar de organizar el proceso de trabajo...» (Barceló, 1989: XX-XXI).

Esta opinión, recogida también por otros historiadores como Carlos Panadero (Panadero, 1991: 135) o Esteban Sarasa (Sarasa, 2008: 164), plenamente aplicable a grandes espacios geográficos, cobra especial fuerza a mi juicio cuando se elabora historia local al tratarse de un ámbito mucho más reducido con un número de fuentes todavía mucho menor.

Remontándonos a la Hispania prerromana, prácticamente nada es lo que se puede decir. Es muy evidente desde épocas prehistóricas los asentamientos en las inmediaciones de los cauces fluviales y cabe suponer el aprovechamiento de sus aguas para la agricultura cuando ésta surgió; sin embargo, no tenemos pruebas que atestigüien con seguridad el riego y únicamente debemos conformarnos con la estampa que realizaba Javier Andreu al hablar de la Bursau celtibérica como «un importante centro de explotación agrícola» y al destacar este autor «la feracidad de su huerta, regada por el Huecha y algunas otras fuentes y manantiales» (Andreu, 1999: 170).

Las sombras del mundo celtibérico se despejan por completo con la llegada de los romanos y la rápida aculturación que experimentó el territorio, lo que, en lo que se refiere al regadío, es especialmente evidente al observar grandes obras 
tales como la presa de Muel (Uribe, Fanlo, Magallón, Bea, Martínez, Reklaityte y Lambán, 2011) o la de Almonacid de la Cuba (Hereza (coord.), 2001).

No contamos con datos específicos sobre el riego romano en lo que hoy es Magallón, si bien las excavaciones realizadas por Isidro Aguilera en Albeta han demostrado sobradamente cómo en esta localidad existió a finales del siglo I d. C. un lugar de culto en el que se realizaban ofrendas dirigidas a una desconocida divinidad relacionada con el agua (Aguilera, 2009: 13-27).

Sin embargo, el descubrimiento más trascendental que evidencia la existencia innegable del regadío en esta región en época romana es el del denominado «bronce de Agón», un documento epigráfico sobre cobre de época del emperador Adriano (117-138). Profundamente estudiado por Francisco Beltrán, consiste en la regulación de una acequia o canal que no se ha localizado, pero que se sabe que se situaba en la margen derecha del Ebro y que afectaba a tres comunidades de regantes: una situada entre Novillas y Gallur; otra en torno a Mallén y la tercera en un lugar indeterminado del mismo ámbito geográfico (Beltrán, 2006a en inglés y 2006b en español).

Resumiendo, no puede decirse nada concreto sobre el regadío en época romana en lo que hoy es Magallón, si bien los hallazgos arqueológicos relacionados con el agua encontrados en poblaciones tan cercanas como Albeta o Agón demuestran con creces cómo se trata de una región bastante romaniza$\mathrm{da}^{5}$ en la que, por lo menos a partir del siglo I d. C., podemos hablar ya de una cultura relacionada con el agua y con la existencia de canales de riego en el curso medio y bajo del río Huecha.

Establecido pues el horizonte del regadío en la región en época altoimperial romana, resulta mucho más complicado rastrear su continuidad tras la caída del Imperio Romano. Sin noticias para el periodo visigodo y a falta de que la arqueología proporcione mucha más información, Carlos Laliena ha hablado de un aprovechamiento generalizado en Aragón de los regadíos romanos «hasta los siglos VIII-IX y de su carácter precursor de los andalusíes» (Laliena, 2008: 57), destacando algún caso de abandono de estructuras hidráulicas que, lejos de utilizarse de manera ininterrumpida desde época romana, dejaron de usarse para volver a ponerse en funcionamiento más adelante tras un lapso temporal. ${ }^{6}$

5 Además de lo dicho, Joaquín Lostal identificó restos romanos en la parte baja de una torre situada en Magallón (Lostal, 1980: 144).

6 Un caso claro y bien estudiado en el que esto sucede es en la cuenca del río Aguasvivas (Sesma, Utrilla y Laliena, 2001) y, con toda probabilidad por su cercanía, también en la del río Martín (Laliena y Ortega, 2005: 165-166 y 203-229 y Rodríguez, 2011: 39-43). 
Sea de manera continuada desde época romana o con interrupciones, es innegable el empuje que los musulmanes dieron al regadío en la margen derecha del río Ebro aguas abajo de Tudela por, entre otros motivos, la mayor aridez de la margen izquierda y porque la derecha se encontraba más alejada de las estribaciones pirenaicas en las que se refugiaban los cristianos (Liauzu, 1964).

No obstante, el silencio de las fuentes musulmanas sobre regadío es prácticamente total y su reconstrucción únicamente puede hacerse a partir de la información que nos ofrecen las fuentes cristianas posteriores a la Reconquista, con todas las distorsiones que ello pueda suponer. Con todo, y teniendo siempre presente este hándicap, Esteban Sarasa ha defendido «la continuidad de una importante red de infraestructura hidráulica, soporte de una actividad económica derivada directamente de la utilización del agua, de la reglamentación de su uso y de los beneficios obtenidos de la misma» (Sarasa, 1989: 635636), a la vez que ha resaltado la gran cantidad de documentos del siglo XII en los que se hace referencia «a situaciones anteriores, "de tiempos de los moros"» (Sarasa, 1989: 643).

Carlos Laliena ha advertido muy oportunamente de la necesidad de tener cuidado con esta expresión prototípica (in tempore sarracenorum) en el sentido en que no debe llevarnos a pensar que los cristianos conquistadores dejaron siempre todo igual y no introdujeron ningún cambio (Laliena, 2009: 284); si bien, admitida esta precaución, la inmensa mayoría de la historiografía coincide en un continuismo generalizado con respecto al periodo andalusí e incluso este mismo autor y Julián Ortega así lo creen al hablar de la Reconquista en el sur de Aragón.?

Efectivamente, ésta es la situación que encontramos en el valle del Huecha durante todo el siglo XII, lo que sabemos con seguridad gracias a la documentación de un monasterio de Veruela que, fundado en 1146, se apresuraría a lo largo de la centuria a apoderarse de prácticamente todo el territorio circundante. Verificando por completo la tesis continuista, los trabajos de Ángel González (González, 1945) y de Amparo Cabanes (Cabanes, 1987) muestran con datos fehacientes cómo, durante el siglo XII y parte del XIII, la población

7 «Aunque no existen datos directos, existen razones para sospechar que una porción significativa, pero no determinada en el momento actual de la investigación, de todo el trabajo acumulado en este laberinto hidráulico podría provenir de fechas anteriores a la conquista aragonesa» (Ortega y Laliena, 2012: 82). 
musulmana ejerció un importantísimo control sobre los recursos hídricos de Magallón, ejerciendo con ello un dominio de las aguas cuyo control, muy especialmente a lo largo del siglo XII, se convertirá en el gran objetivo por parte de los conquistadores cristianos.

Resumiendo, la arqueología permite establecer un horizonte en torno al siglo I d. C. gracias a hallazgos en las inmediaciones de Magallón que demuestran la existencia de un culto al agua, además de un canal de riego que discurriría relativamente cerca. Lo cierto es que, hasta más de mil años después, esto es, hasta el siglo XII, no hay ningún dato y lo que puede decirse con cierta seguridad es que los cristianos que conquistaron el territorio en época de Alfonso el Batallador encontraron que el regadío se había ido desarrollando (o por lo menos, manteniendo) por parte de los musulmanes que se habían asentado en el valle del Huecha en épocas anteriores. Es sólo a partir de este punto cuando puede elaborarse una historia con datos plenamente fidedignos.

\section{El regadío medieval en Magallón tras la Reconquista}

\section{a) Las acequias y sus grupos sociales dominantes}

No me extenderé en una descripción de canales, azudes, acequias y trazados, habida cuenta de que la infraestructura hidráulica de Magallón ya ha sido descrita por diversos autores en muchas ocasiones, por lo que hacerlo supondría repetir una vez más datos que ya se han dado varias veces en el pasado y que incluso figuran ya en el vigésimo primer número de Aragón en la Edad Media. ${ }^{8}$ Sirva, no obstante, la indicación de que el regadío medieval en Magallón tenía que ver fundamentalmente con tres acequias: la de Marbadón, la del Plano y la del Lugar.

Conocido esto, una cuestión que considero importante es dilucidar si, cuando hablamos del regadío medieval en Magallón, nos estamos refiriendo a una realidad controlada por los mudéjares o por los cristianos. Considerando que, en realidad, el regadío como tal no pertenecía a nadie sino que lo que estaban en manos de unos o de otros eran las tierras irrigadas, la realidad es que la documentación medieval magallonera muestra una adaptación mutua de cristianos y musulmanes a la economía agraria del valle del Ebro.

8 Véanse, por ejemplo, García, 1960: 126-127 (desplegable entre ambas páginas); Teixeira, 1995: $306-$ 326; Carranza, 2009: 48-51 y Rodríguez, 2009: 227-231. 
Efectivamente, la documentación del monasterio de Veruela ha demostrado cómo, durante el siglo XII, cuando los monjes quisieron hacerse con el control de las inmediaciones de Magallón, se encontraron en muchas ocasiones con el binomio agua y musulmanes. Los ejemplos lo dejan muy claro: en junio de 1168, Jucef de Farag vendió a Veruela una pieza de tierra en Mazalcoraz y dos azumbres de agua; en septiembre de 1177, Axa hizo lo propio con una pieza en el mismo sitio y un azumbre; en 1187 Alí y sus hermanos empeñaron cuatro azumbres, mientras que en junio de 1199 los religiosos acordaron con Farag de Alhacim y su familia una repartición de las aguas de Mazalcoraz (Cabanes, 1987). ${ }^{9}$

No obstante, lo cierto es que, cuantitativamente, tampoco podemos hablar de una supremacía clara mudéjar para el regadío magallonero en el siglo XII porque, frente a todos estos documentos en donde aparecen musulmanes, encontramos otros tantos con protagonistas cristianos: en enero de 1168, don Lope donó cuatro piezas de tierra en Ginestar y cuatro azumbres de agua; en 1169, este mismo personaje empeñó otros cuatro azumbres; en enero de 1173, María Atarés vendió a los monjes otro azumbre, confirmando la operación en junio de $1182 \ldots{ }^{10}$

De una manera o de otra, ya estuviera inicialmente en manos cristianas o en musulmanas, lo cierto es que la tendencia a lo largo de la centuria será la de que la institución feudal por excelencia del valle del Huecha, el monasterio de Veruela, so pretexto de que la granja de Mazalcoraz les pertenecía, arrebate a los mudéjares magalloneros las mejores tierras irrigadas. En este sentido, el intercambio de propiedades de octubre de 1175 por el que Jucef y Abderramán dieron a los religiosos dos piezas de tierra que lindaban con la acequia mayor de Magallón a cambio de recibir cuatro donde el agua brillaba por su ausencia es una buena muestra de lo que afirmo.

Esta tendencia parece completarse en el siglo XIII. Salvo un caso de agosto de 1245 por el que el abad de Veruela compró a un mudéjar de Magallón un octavo del agua que poseía en la acequia mayor (González, 1945: 79-83), lo cierto es que los protagonistas de los documentos son ya exclusivamente cris-

9 El azumbre, se trata, según el diccionario de la R. A. E., de una «medida de capacidad para líquidos, que equivale a unos dos litros».

10 Todos los documentos de Veruela de los siglos XII y XIII están transcritos en Cabanes (en prensa). En tanto esta publicación ve la luz, la documentación en pergamino puede consultarse en Kiviharju, 1989. Para un comentario global de toda esta documentación, véase Rodríguez, 2010. 
El regadío en Magallón (Zaragoza) hasta el siglo xv y la documentación medieval sobre agua...

tianos y lo mismo sucede en la Baja Edad Media, época en la que los mudéjares magalloneros desaparecen por completo de la documentación.

En resumen, en Magallón sólo se puede hablar de presencia musulmana en tierras de regadío durante el siglo XII y, como mucho, en la primera mitad del XIII. En todo este periodo, se observa cómo las grandes instituciones feudales, con el monasterio de Veruela a la cabeza, llevaron a cabo un proceso que tenía por objetivo el acaparamiento de los recursos hídricos y la adquisición de las mejores tierras en claro detrimento de los mudéjares. La consecuencia era muy evidente y así lo plasma claramente la documentación: a partir de 1250 , el regadío magallonero estaba completamente dominado ya por los cristianos.

\section{b) La conflictividad social y la lucha por el agua}

No resulta necesario explicar la importancia que siempre ha tenido el agua para unos seres humanos que, ya desde el abandono de los abrigos y cuevas prehistóricas, crearon asentamientos instalados cerca de los cursos fluviales. Es por este motivo que el agua, por lo general un bien escaso que debía repartirse entre muchos y máxime en lugares donde no abundan las precipitaciones, fue durante toda la Edad Media motivo de disputa por parte de las comunidades instaladas en el valle del Huecha.

De esta manera, encontramos continuamente en este cauce una feroz disputa entre todos los regantes, con multitud de acusaciones cruzadas entre localidades que, en muchas ocasiones, obligaron a la intervención del rey o de altos miembros de la nobleza o de la jerarquía eclesiástica con el fin de resolver los conflictos, lo que, por cierto, no siempre consiguieron.

Al mismo tiempo y en estrecha relación con todos estos pleitos, las distintas localidades situadas en las inmediaciones del Huecha se vieron obligadas a llegar a acuerdos entre ellas para repartirse el agua y a establecer toda una serie de normas que dejaran bien claro cuándo podía y cuándo no regar cada una, quiénes debían responsabilizarse del buen estado y de la limpieza de canales y acequias, quién o quiénes debían ser los garantes de que se acordara lo pactado...

No entraré a detallar todos los conflictos, pactos, acuerdos... que abarcaron desde el nacimiento del Huecha hasta su desembocadura en el Ebro, puesto que los citados estudios de Guillermo Carranza o la Historia de Borja de Pedro Rújula y Herminio Lafoz ya lo hacen con bastante detenimiento. 
No me referiré aquí a los enfrentamientos que los magalloneros de la Edad Media mantuvieron con el monasterio de Veruela al pertenecer a éstos la granja de Mazalcoraz por la donación que Alfonso II les hizo a los monjes en 1177. Esta decisión real y la actitud acaparadora de un monasterio que intentó siempre apoderarse de las mejores tierras que rodeaban Magallón condenó a los de la villa a tener que entenderse siempre con los religiosos por el uso del agua para regar (Rodríguez, 2009).

Además de con los monjes verolenses, Magallón mantuvo también enfrentamientos con las localidades vecinas y, muy en especial, con Alberite de San Juan, población perteneciente primero a los templarios y posteriormente a los hospitalarios tras la disolución de aquéllos. La clave de los enfrentamientos era un azud que se encontraba en Alberite y de cuyo mantenimiento en buen estado dependía que a Magallón le llegara el flujo necesario de agua por ser este lugar el nacimiento de la acequia del Plano.

Considerando que a los magalloneros les interesaba que el azud estuviera en buenas condiciones - e incluso a los monjes de Veruela, que en este tema se asociaron con los de Magallón al compartir intereses - y que para los de Alberite era una cuestión sin importancia puesto que no les afectaba, ambas localidades estuvieron enfrentadas en diferentes momentos por este asunto, llegando incluso a intervenir la monarquía para obligar a los alberitanos al correcto mantenimiento de la infraestructura hidráulica.

No obstante, no todo fueron enfrentamientos entre Magallón y Alberite, puesto que, en realidad, en temas de regadío, la única solución viable para todos era la de ponerse de acuerdo. En este sentido deben entenderse los acuerdos suscritos entre ambos lugares en 1249 o dos pergaminos de 1459 conservados en el Archivo Municipal de Magallón: ${ }^{11}$ en el primero, ambas

11 Salvo que se indique lo contrario, todos los documentos a los que hago referencia a partir de este punto pertenecen a la colección de pergaminos conservados en el Archivo Municipal de Magallón. Todos ellos se custodian ordenados cronológicamente en unos cajones de grandes dimensiones y carecen de signatura archivística, por lo que la única referencia es su data.En este sentido, la gran mayoría de estos pergaminos cuenta con una datación y regesta elaborada por Juan Antonio Frago (Frago, 1980a: 225227), quien también se encargó de la publicación de alguno de ellos (Frago, 1980b: 401-414).

Junto a éstos, un buen número de pergaminos se guardan en el Sindicato de Riegos de Magallón. Carentes igualmente de referencia archivística, lo único que se puede decir de ellos para saber a cuál nos referimos es su datación, por lo que, a fin de diferenciar éstos de los del Archivo Municipal y a fin de no sobrecargar el artículo de innecesarias notas a pie de página que únicamente dirían en qué lugar se encuentran y de qué año son, identificaré los del Sindicato de Riegos con un asterisco (*) en el texto. Tantos unos como otros han podido consultarse gracias a las gestiones realizadas por José Ignacio Sauca, a quien agradezco enormemente su colaboración. 
localidades llegaron a un acuerdo sobre la acequia del Plano, mientras que en el segundo Alberite vendió a Magallón el derecho a construir en su término una acequia para regar los montes comunales.

La administración de la acequia de Marbadón fue otra de las cuestiones que obligó a los pueblos a buscar el entendimiento, máxime después de que el monarca Pedro III obligara en junio de 1280 a los de Alberite, Bureta y Albeta a contribuir junto a los de Magallón en el mantenimiento de dicho canal de riego. ${ }^{12}$

Como consecuencia de ello, todas las localidades implicadas acordaron en 1310* las condiciones de riego sobre esta acequia, estableciéndose un especial control a Albeta, la primera de las cuatro a las que llegaba el agua y, por consiguiente, la primera que podía hacer un uso abusivo del agua en detrimento de las otras tres restantes. Es en sentido en el que deben entenderse, entre otras cosas, la prohibición que se les hace de desviar el agua por cauces alternativos o la obligación de actuar firmemente contra cualquier desperdicio de la misma.

No obstante, no debe perderse de vista que la acequia de Marbadón nace en Borja, por lo que, al margen de lo que pudiera hacer o no Albeta, los primeros que utilizaban esta agua eran los de esta localidad. Con un especial protagonismo en su administración, en 1342 los concejos de Magallón, Alberite, Bureta y Albeta confiaron al borjano Pedro Blasco el cuidado del azud y de la acequia de Marbadón, a la par que un segundo documento de este mismo año recoge la reglamentación que se hizo del uso de sus aguas entre las localidades por las que discurría dicha acequia.

Pese a ello, esta primacía ejercida por Borja en lo que se refiere a la acequia de Marbadón la convirtió casi siempre en el «enemigo común»de Albeta, Bureta, Alberite y Magallón, localidades que aparecen en la documentación constituyendo una hermandad. Un documento de 1320 que figura en el apéndice documental evidencia cómo los borjanos habían abierto canales de riego alternativos para desviar el agua, tomar más de la que les correspondía e impedir su llegada a las poblaciones de aguas abajo, entre ellas, Magallón.

Con todo, Borja casi siempre tuvo en la Edad Media la primacía en lo que se refiere a la administración de la acequia de Marbadón: como se ha dicho, en 1342 aparece un borjano como responsable de su cuidado; en 1385, Pedro IV

12 Archivo de la Corona de Aragón (ACA), Real Cancillería, Pedro II [III], reg. 48, fol. 45v. (documento de 14 de junio de 1280). 
apoyó a Borja en cualesquiera litigios que tuviera por las aguas del Huecha y perdonó a los borjanos todas las multas que se le habían impuesto en pleitos contra Magallón, Bureta, Alberite y Albeta por el regadío; ${ }^{13}$ en $1431, *$ otro borjano vendió a los de Albeta y Magallón el derecho de abrir nuevamente la acequia...

Si con bastante frecuencia hubo en la Edad Media enfrentamientos entre Borja y Magallón por diversas causas y ya en marzo de 1289 el rey Alfonso III ordenó al sobrejuntero de Tarazona que pusiera orden entre ambas villas por los daños mutuos que se estaban causando ${ }^{14}$ la simpatía que tradicionalmente mostró la monarquía por Borja y el hecho de que los reyes casi siempre dieran la razón a los borjanos en cualquier cuestión relacionada con el regadío - excepto Jaime II en 1320 - eran factores que provocaban el descontento en unos magalloneros quizá demasiado acostumbrados a perder derechos frente a los privilegiados del Huecha, esto es, Veruela, Borja y los hospitalarios de Alberite.

Quizá buscando la neutralidad que la monarquía no les brindaba y ante las malas perspectivas que generaba el hecho de que Alfonso $\mathrm{V}$ concediera en 1438 el título de ciudad a Borja ${ }^{15}$ en 1446 fue el arzobispo de Zaragoza, Dalmau de Mur, y no el monarca el que actuó de juez entre ambas localidades, estableciendo el turno de riegos que debería seguirse y, quizá lo más importante, facultando a los de Magallón a que pudieran adentrarse en los términos de Borja para efectuar las reparaciones que fueran necesarias a fin de que les llegara el necesario flujo de agua. ${ }^{16}$

Resumiendo, la documentación es prolija y muy extensa como para entrar en demasiados detalles, si bien queda muy claro cómo el aprovechamiento del agua siempre ha sido un tema bastante controvertido y cómo cualquier enfrentamiento que pueda existir hoy en día por ello no es algo nuevo, sino que hunde sus raíces en la época medieval.

\section{c) Los turnos de riego}

Como se ha visto, la inmensa mayoría de los pleitos que tuvieron lugar entre Magallón y sus vecinos fueron fundamentalmente para establecer unos

13 Archivo Municipal de Borja (AMB), doc. PL3-0011 (documento de 18 de abril de 1385).

14 ACA, Real Cancillería, Alfonso II [III], reg. 81, fol. 47 (documento de 1 de marzo de 1289).

15 Aunque hay abundante bibliografía sobre esto, véase principalmente Falcón, 2010.

16 AMB, docs. 91-3K, 456-2, 456-4, 458-30, 458-30A y 458-31 (documentos de 5 de mayo de 1446). Igualmente, una copia de esta sentencia se conserva en el Sindicato de Riegos de Magallón. 
turnos a la hora de regar y saber quién debía hacerlo a cada momento. Lógicamente, estos turnos (denominados en la documentación como adores) varían en función de con quién se estaba llegando a un acuerdo, por lo que convendrá hacer de nuevo el repaso por el tema de la conflictividad.

Considerando que todo lo relativo a los turnos acordados entre Magallón y la granja de Mazalcoraz ya se estudió con anterioridad (Rodríguez, 2009: 233236), la acequia de Marbadón adquiere, una vez más, pleno protagonismo. Así, la sentencia de 1446 pronunciada por el arzobispo de Zaragoza para regular el riego entre Borja y Magallón establecía normas para el periodo comprendido entre el 1 de abril y el 24 de junio, periodo en el cual borjanos y magalloneros tenían una semana cada localidad de manera alternativa para utilizar el agua, debiendo además los de Magallón permitir que, en dos ocasiones durante ese periodo, los de Albeta y Ainzón pudieran regar excepcionalmente unos campos de lino y cáñamo.

Fuera de este periodo, ambas localidades podían utilizar libremente el agua sin estar condicionados por ninguna norma ni turno, excepción hecha de los meses de octubre y noviembre en los que el agua correspondía exclusivamente a los magalloneros. Disfrutando así pues Magallón de semanas alternativas de riego entre el 1 de abril y el 24 de junio, en realidad, el agua de Marbadón no le pertenecía en exclusiva, porque debía compartirla con Albeta, Bureta y Alberite, tal y como aparece claramente establecido en la concordia de 1310, ratificada a su vez en 1322 y 1488 .

No puede decirse que estos pactos duraran para siempre y que se respetaran en todos los momentos posteriores, puesto que los siglos venideros están llenos de nuevos conflictos que, una vez más, solían solucionarse estableciendo nuevos turnos de riego o revalidando los existentes. Sin embargo, lo cierto es que la vigencia de estos acuerdos medievales, tan lejanos en el tiempo, ha llegado hasta los siglos XIX y XX e incluso hasta la actualidad, como se observa en detalles concretos como la ratificación que el Juzgado de Primera Instancia de Borja hizo en agosto de 1884 de la sentencia de 1446, a la que se sigue haciendo alusión en las Ordenanzas de Riego establecidas por Magallón en 1993 (Ordenanzas, 1993). ${ }^{17}$

17 No es éste el único caso, puesto que, como ha destacado Juan F. Utrilla, las ordenanzas de la comunidad de regantes de Belchite que fueron aprobadas el 30 de marzo de 1894 continen no pocas reminiscencias de la época medieval (Utrilla, 1996: 92 y 109-110). 


\section{d) El control y la vigilancia del agua}

En los espacios hidráulicos en donde varias comunidades compartían una misma agua era necesaria la existencia de responsables encargados de vigilar que se cumplieran las disposiciones acordadas en las sentencias y/o a los que se encomendaba una misión específica tal como la limpieza de cauces o la supervisión del estado de la infraestructura de riego o una cuestión trascendental como era velar por el cumplimiento de los turnos de riego, persiguiendo a los posibles infractores. Estos encargados reciben el nombre más frecuente de zabacequias.

Lógicamente, el nombramiento de estos responsables traía consigo multitud de problemas en el sentido en que cada comunidad procuraba colocar a su propio candidato para, de esta manera, captar su simpatía y posible flexibilidad así como para garantizar la férrea vigilancia de los regantes.

Así, ya indiqué cómo, ante la pretensión de los magalloneros de que el zabacequia de la granja de Mazalcoraz fuera de Magallón, en 1382 se estableció que fuera elegido por el granjero verolense, pero con la condición de que fuera vecino de Magallón y de que jurara su cargo ante las autoridades de ambos lugares, comprometiéndose a custodiar las heredades de los cistercienses, asegurar el cumplimiento de los turnos de riego y denunciar cualquier infracción que pudiera cometerse en un plazo máximo de tres días (Rodríguez, 2009: 237).

En lo que se refiere a las relaciones entre Magallón y los otros municipios, el zabacequia también jugó un papel de gran importancia. Por citar dos ejemplos de los documentos que figuran en el apéndice documental, en 1249 se estableció que los de Alberite podían disponer de huertos en los términos de Magallón, siempre y cuando el riego de éstos estuviera supervisado directamente por el zabacequia magallonero: per manum çavaçequie.

Igualmente, la concordia de 1310 establece que los de Albeta tenían derecho a utilizar el agua de la acequia de Marbadón para regar unas plantaciones de lino y cáñamo que poseían, quedando una vez más encargado este oficial magallonero de vigilar que el agua se utilizara para lo que estaba previsto y no para otros fines.

En cuanto a esta acequia de Marbadón, conviene recordar que Borja ejercía una clara superioridad por los motivos que se han citado y, en este sentido, debe entenderse el encargo que Magallón, Alberite, Albeta y Bureta le hicie- 
El regadío en Magallón (Zaragoza) hasta el siglo xv y la documentación medieval sobre agua...

ron al borjano Pedro Blasco en 1342 al responsabilizarle del cuidado del azud y de la acequia.

No obstante, hay que señalar que la sentencia de 1446 supuso un punto de inflexión en este tema y que la balanza, quizá demasiado inclinada hasta el momento hacia el lado de Borja, se equilibró en parte cuando el arzobispo de Zaragoza facultó a los vecinos de Magallón a que todos los meses de marzo nombraran a uno o dos zabacequias que ejercerían por un periodo de un año y que debían jurar su cargo ante las autoridades borjanas.

Otro tema del que también nos habla la documentación es el de las alfardas o cequiajes, esto es, los impuestos que debían abonarse para tener derecho a regar. En este sentido, el documento más completo es la sentencia arbitral de 1487 entre Magallón y Veruela que ya estudié en 2009 y que establece que la competencia de recaudar el impuesto correspondía a Magallón pero con la obligación de avisar al granjero de Mazalcoraz por si quería supervisar esta función, pudiendo hacerlo la villa en solitario en el caso de que los monjes declinaran esta posibilidad (Rodríguez, 2009: 240-241).

Por otra parte, otro tema que merecería especial atención sería todo lo referente a los derechos de tala, esto es, y tal y como se explica con detalle en la concordia de 1310, el derecho que tenían los perjudicados de arrancar lo que estuviera plantado en aquellas tierras que hubieran sido regadas fraudulentamente, cuando no les correspondía o sin cumplir las normas establecidas.

En este sentido, aunque no lo he incluido en el apéndice documental por sus considerables dimensiones, un documento de 1483 conservado en el Archivo Histórico Provincial de Zaragoza demuestra cómo, a finales de la Edad Media, esto estaba plenamente vigente después de que el concejo de Mallén, situado prácticamente en la desembocadura del Huecha en el Ebro, se encargara de la tala de dos pieças de cañamo e pieça sembrada de fabas en los términos de Magallón por haber sido regadas indebidamente ${ }^{18}$.

\section{Conclusiones}

Resumiendo, durante la Edad Media, Magallón no fue más que una villa aragonesa más que tuvo que afrontar los mismos problemas que las demás 
poblaciones del reino, siendo el primero de ellos el de su subsistencia en un mundo en el que los magalloneros no estaban solos. Todo lo contrario, con una economía fundamentalmente agraria y en un territorio en el que, en un espacio muy reducido, coexistían entidades pertenecientes a jurisdicciones muy diferentes, el agua aparece como un bien al que nadie podía permitirse el lujo de renunciar.

Hacer historia del regadío equivale a hacer historia económica y social. En primer lugar, económica porque estamos hablando de la riqueza que podían generar todos estos municipios basándose en la agricultura, algo para lo que el agua tiene una importancia capital. En segundo lugar, se trata de historia social porque todos estos documentos evidencian una serie de comportamientos colectivos en los que los que se aliaban para un asunto, al mismo tiempo se querellaban para otro, amén de evidenciar toda una serie de relaciones personales mucho más complejas de lo que se ve a simple vista.

Por otra parte, prestar atención a los muchos documentos que todavía permanecen inexplorados por estar ubicados en lugares insospechados, porque no se encuentra quien sea capaz de leerlos e interpretarlos o por una mezcla de circunstancias de muy diversa naturaleza nos demuestra que todavía queda mucho trabajo por hacer y, en el caso del regadío, a mi juicio, aun quedan muchas páginas por escribir.

En el caso de Magallón es más que evidente y, en este sentido, son muchos los pergaminos de su archivo municipal y de su sindicato de riegos que aguardan pacientemente su transcripción y estudio. No obstante y pese a todo, lo expuesto hasta aquí constituye una muestra eficaz de cómo el agua, sin la cual no es posible la supervivencia, forma una parte inseparable de la historia magallonera. 
El regadío en Magallón (Zaragoza) hasta el siglo xv y la documentación medieval sobre agua...

\section{Apéndice documental}

1249, octubre.

El concejo de Magallón acepta que los de Alberite disfruten de treinta y seis huertos en sus términos y que los rieguen, a cambio de que no los intenten ampliar y de que los alberitanos se encarguen del mantenimiento en buen estado de un azud ubicado en su término del que dependía el riego de los magalloneros.

Archivo Municipal de Magallón (AMM). Copia elaborada con letra del siglo XV. Pergamino con algún desperfecto de escasa importancia.

In Christi nomine. Notum sit cunctis quod nos dompnus Sancius d'Antillon, dominus de Ganyallur, et dompnus Martinus Eximini de Novar et dompnus Michael et dompnus Petrus Ariol et fratres militie Templi, arbitri electi ex parte Belengarii [de] / Monte Accuto, comendator de Ambel et de Alberit, et fratris Petri Urgel et aliorum fratrum de Alberit et nos Didacus Petri, comendator Sante Marie Cesarauguste, et dompnus Petrus Justani et frater Vitalis, monachus Berole, et frater Sancius, grangerius / de Meçalcoraig, electi arbitri ex parte Petri, iustitie de Magallon, et totiusque concilii eiusdem ville super quibusdam contentionibus inter eos ortis tandem auditis rationibus hinc et inde et plenarie intellectis, habito etiam diligenti tractatu sapientium, / de consilio et de mandato dompni Guillermi de Cardona, magistri militie Templi, de asensu et voluntate dicti comendatoris et aliorum fratrum de Alberit, de asensu etiam et voluntate dicti iustitie et concilii supradicti, amicabiliter compponendo inter eos / dicimus quod cum fratres predicti et homines sui haberent triginta sex ortos in Alberit inter çequiam de Magallon et Ocham de amicabili asensu utriusque partis, dicimus quod ortus Fortuni de Enyego et dompna Francha rigentur uno mane, ortus / qui fuit Sante Christine rigetur alio mane, ortus dictorum fratrum rigetur alio mane, ortus Dominici de Iacca et Petri de Vera rigentur alio mane, ortus Marie del Corral rigentur alio mane, ortus de Çalema de Irco rigetur alio mane.

Alii viginti / octo orti qui remanent, siliçet (sic), ortus Mathei Vitalis de Cornellon, Luppi de Sciornat, Gracie Sancii Navarro, usque ad saliçes Dominici Franchii, Michaelis Diaz et de Çalema Calon usque ad saliçes Guillermi de Mora, de Muça Calbo, de Muca / de Ocha et ortus elie pars populata et alter ortus de Muça de Ocha, de Bonsour de Cornellon, Dominici de Tomas, Michaelis de Cortes, < domini (sic) Marie, Iohanis Dominici del Corral, Michaelis de Torres>, Andrei, Marie Bernardi et filiorum, Martini de Balbuen, Martine de Marcho de Aznar de Bierlas, / Martini de Burueta, Iohanis de Ambel, Michaelis d'Epila, Martini Guillermi, Pascasii de Andreu, Dominici de Iacca rigentur tres uno mane et tres alio mane et sit per ordinem subsequenter et quod aquam istam recipiant homines de Alberit et fratres / per manum çavaçequie de Magallon e per certas filas a dicto çavaçequia constitutas et per certa signa et quod dicti fratres de Alberit et homines qui non aumentent de cetero dictos ortos nec valeant aumentare ( sic) nec rigent serveas in eisdem ortis / constitutas ubi sunt saliçes et bergales nec rigent aliquam aliam terram heremam vel populatam cum aqua illius çequie de Magallon.

Et quicumque de Alberit rigaverit dictos ortos vel aliquam aliam terram ultra quod superius dictum est cum aqua / çequia supradicte et si de die est peytet quinque solidos domino aque; si de nocte, sexaginta solidos. Nunc est consuetum in Magallon quam caloniam dominus aque petat fratri tenenti locum comendatori in Alberit et frater dictus faciat ei dari calonia / vel pignora valentia caloniam supradictam. 
Item, de amicabili partium voluntate, dicimus quod dicti fratres duos campos quos habent, uno supra molendinum qui afrontat ex una parte in çequia veteri de Magallon, ex altera parte in cequia que / vadit inter campum et sotum, ex tertia parte in çequia de Magallon que vadit ad molendinum, ex quarta parte in via que vadit ad molendinum; alter campus est subtus molendinum qui afrontat ex duabus partibus cum cequis de / Magallon et ex alia parte cum via publica rigent in prima çafra mensis aprillis in die de alhamiz tantum semel et in prima çafra mensis madii et in ultima mensis madii in die de alhamiz quartam partem aque recipiant / per manum çavaçequie de Magallon tali modo quod dictus çavaçequia claudat in tantum gamellam illius çequie que vadit ad Magallon, quod çequiam que vadit ad canalem nichil amitat de aqua sua.

(It?)em dicimus quod dicti fratres teneant viam / bonam apertam inter çequiam et dictos ortos (quam?) possint homines libere transire ad custodiendum aquam.

Item, de amicabili partium voluntate, dicimus quod çavacequia de Magallon sit quolibet $\mathrm{u}[\mathrm{sq}] \mathrm{ue}$ in ortu solis ad filas per quas / homines de Alberit debent recipere aquam ut tam de manu suam recipiant, sicut superius comentatur. Et si pre[dictus] çavaçequia ora statuta non fuisset ibi nichilominus homines de Alberit rigent ortos sine calonia secundum / formam superius constitutam.

Item, de amicabili partium voluntate, dicimus quod sepedicti fratres et homines de Alberit semper manuteant açutem de Magallon quam odie ( $\mathrm{sic}$ ) manutenent et cequiam usque ad [gam] ellam ita quod aliquo modo aqua / non perdatur. Et si perdetur, teneantur eam hominibus de Magallon emendare.

Item, dicimus quod açut antiqua de Magallon et açutiello del alherma remaneant de Magallone sicut odie sunt ita tamen quod cum oppus fuerit homines acci/piant per ocham per treytum et vocata sicut facere consueverunt, exceptis arboribus.

Item, de amicabili partium voluntate, dicimus quod quidquid dampni una pars alteri intulit usque hodie vel (ilegible) ab utraque partium voluntate / sit indultum.

Nos igitur dicti comendator et fratres per nos et succesores nostros dictam compositionem primitius bona fide perpetuo observare. Et, si forte in aliquo frangeremus vel observare nollemus, obligamus nos solvere penam in instrumento compromissi (sic) / expressam.

Et nos, dictum concilium de Magallon, bona fide promittimus illud idem. Et, si forte in aliquo frangeremus vel observare nollemus, obligamus nos solvere penam in instrumento compromissi expressam.

Testes huius rey ( sic) sunt dompnus Petrus / Uger et dompnus Guillermus, vicinus de Alberit, fratres militie Templi, et dompnus Eximinus Luppi de Burgia, filius dompni Petri Alvari, et frater Petrus de Magallon, sacrista et monachus Berolensis, et dompnus Rodericus de Agon, miles, et dompnus / Petrus Iohanis, vicarius de Magallon, et Petrus Abbat, clericus de Magallon, et dompnus Carbonel, vicinus de Magallon.

Actum est hoc mense octobris era millessima ducentesima octuagessima septima.

Ego Iohanes Petri, publicus / notarius in Magallone, hoc scripsi et hoc sig(signo)num feci. 
El regadío en Magallón (Zaragoza) hasta el siglo xv y la documentación medieval sobre agua...

1310, abril, 21 .

Los concejos de Magallón, Alberite y Bureta por un lado y el de Albeta, por el otro, acuerdan las condiciones de uso del agua de la acequia de Marbadón, los turnos de riego y las sanciones que debian imponerse a los infractores.

Sindicato de Riegos de Magallón (SRM). Un documento original en gótica semicursiva aragonesa; una copia con escritura gótica aragonesa de la segunda mitad del siglo XIV y otra copia en escritura humanística datada en junio de 1488. Pergaminos. Los más antiguos presentan roturas y manchas de humedad. ${ }^{19}$

Sepan todos quantos estar present carta veran como yo don Pero Garcia, clerigo, e yo don Johan Perez d'Alvos, cavallero, e yo don Domingo de Justa e yo Franquo Perez de Cimorra e yo don Guyllem d'Enganz, veçinos de Magallon e procuradores del concello del dito logar de Magallon con carta publica de procuracion feyta por mano / de Jayme Mallen, notario publico de Magallon, la tenor de la qual yes a tal:

Inserta carta de procuración de 17 de abril de 1310.

E yo don Pero Vera e yo don Domingo Allias, veçinos de Alberyt e procuradores del conçello del dito logar d'Alberyt con carta publica de procuraçion feyta por mano de Pero Ferrandez, notario publico de / Alberyt, el tenor de la qual yes a tal:

Inserta carta de procuración de 17 de abril de 1310.

E yo don Pedro Don Yennego, veçino de Burueta e procurador del concello del dito logar de Burueta con / carta publica de procuracion feyta por mano de Pero Garçes, notario publico de Burueta, la tenor de la qual es a tal:

Inserta carta de procuración fechada el 22 de abril de $1310 .^{20}$

E nos, sobreditos don Pero Garçia e don Johan Perz d'Alvos, cavallero, e / don Domingo de Justa e Franquo Perz de Cimorra e don Guyllem d'Engans, procuradores del conçello de Magallon, e nos, ditos don Pero Vera e don Domingo Alyas, procuradores del conçello de Alberyt, e yo, dito don Pedro Don Yennego, procurador del concello de Burueta, e por el poder a quis cada uno de nos dado e atorgado en las sobredichas procura/ciones femos abiniença e composiçion con vos dona Taresa Gonçalvez de Vera, sennora de Albeta, e con vos vos (sic) don Juçe d'Almalhahç e con vos don Mahoma d'Almalhahç e con vos Avdalla d'Avencantar e con vos don Çayt d'Almilluel, moros de Albeta, e con toda el aljama del sobredito logar de Albeta sobre el / agua de la çequia de Marbadon.

Primerament, lexadas todas cosas que andadas son entro a qui syan desfeytas las poças e collidas dally do son e que sean feytas sobre la çequia dios la villa de Albeta en tal manera quel agua de las poças torne todavia a la madre e que nunca en ningun tiempo sean feytas / poças synon ally do la hermandat lo signara.

19 La transcripción que aquí figura está elaborada a partir del documento original.

20 Literalmente, la fecha de este documento inserto es IX dias en la exida del mes de abril era milesima $C C C^{a} X L^{a} V I I I^{a}$, si bien esto no puede ser correcto si se tiene en cuenta que la concordia está datada el 21 de abril y que ningún documento inserto puede ser posterior a aquel en el que se encuentra copiado. 
E sy, por ventura, atentado sera en algun tiempo por el sennor de Albeta ho por qualquiere otro del dito logar de mudarlas daquel logar do agora seran asignadas por la hermandat, quel coste de calonia LX solidos de jaqueses, de la qual calonia seya la meytat del sennor / de Albeta daquel qui por tiempo la terra e la otra meytat de aquellos que perdran el agua de los iusanos, es a saber, pora Magallon e pora Alberyt e pora Burueta e que pueda la hermandat pennorar al sennor de Albeta o a qualquiere de aquel logar qui aquello atentara de fer por la sobredita calonia, en yermo o en poblado sus penno/ras sines calonia alguna. Encara, la hermandat que puedan desfer las ditas poças e tornalas (sic) a aquel logar do agora por ellos seran asignadas.

Encara, queremos que en aquellos VII dias que los omes de Magallon e de Burueta e de Alberyt e de Albeta an en el agua de la cequia de Marbadon de la canal de Albeta enta iuso, / la dita agua a yr en veç del primer dia de abril entro a la fiesta de Sant Johan Babtista, segunt y es acostumpnado, que los omnes de Albeta a todos tiempos jamas rieguen e puedan regar en cada uno anno por sy del primer dia de abril entro a la fiesta de Sant Johan Babtista dos vegadas lynos e cannamos sobre lur veç, / en quales açafras que ellos mas querran, con tal condiçion que ellos que reciban el agua el primer dia del açafra al sol exido por mano de los çavaçequias de Magallon e que rieguen los ditos lynos e cannamos ygualment fila delant.

E sy, por ventura, los cannamos no eran de regar en el tiempo de los lynos, ellos que puedan pren/der el agua en el otra açafra por los cannomos, segunt que dito y es, el primer dia del açafra.

E sy, por ventura, los çavaçequias de Magallon non fuesen ally al sol exido, que los omnes de Albeta puedan prender el agua sines enbargamiento nenguno, segunt que de suso dito y es, e qualesquiere de Albeta ho de Magallon ho de Burueta ho de / Alberyt que regaran con la dita agua sy non fila delant fila, segunt acostumpnado y es, ho otro fruyto nenguno, synon lo que de suso dito y es, que todos los otros de la hermandat talen e puedan talar todo aquello (lac: que) se regara sin calonia e henbargamiento nenguno. E en qualquiere destos logares que tal regar sera feyto / que los mesegueros del logar entren primero a fer la tala con los otros mesegueros de los otros logares e desy todos los otros que entrar y querran. E sy los del lugar no y querran entrar, que los otros de la hermandat puedan talar sines henbargamiento nenguno.

E sy, por ventura, los de Borja o de Aynçon / regaran con el agua de los VII dias de Magallon e de Alberyt e de Bururueta (sic) e de Albeta, que todos ensenble la hermandat vayan todos poderosament e varonilment a talar todo aquello que se regara con la dita agua de la canal enta suso.

E encara que sean tenidos los omnes de Albeta de ayudar a man/tener e a reparar el açut e a todas las otras cosas que mester seran en la dita çequia a pro de la hermandat.

Item encara, que qualquiere que regar depues de Sant Johan quando aya regado su canpo o sus ortalizas que torne el agua a la madre e, si no la y torna a la madre, quel coste de calonia de / dia $\mathrm{V}^{\mathrm{o}}$ solidos e de nueyt LX solidos, de la qual calonia sia <la $>$ meytat del sennor de Albeta o de aquel qui por tiempo la terra e la otra meytat de los iusanos que perdran el agua, es a saber, pora Magallon e pora Alberyt e pora Burueta. E el sennor de Albeta, aquel qui por tiempo sera, que faga collir la calonia de la çequia de Marbadon de sus / vasallos sines remedio alguno. E, sy no lo fiçiese, que la hermandat lo puedan pennorar, en yermo o en poblado, doquiere que seran sus pennoras trobadas sines calonia alguna.

Item encara, y es condiçion entre nos que qualquiere de Albeta que ytara el agua a perdiçion de Sant Johan adelant, y es a saber, en canpo con vinna o en olivar / o en qualquiere otro logar 
El regadío en Magallón (Zaragoza) hasta el siglo xv y la documentación medieval sobre agua...

que el sennor aya, quel coste de calonia de dia $\mathrm{V}^{\circ}$ solidos e de nueyt LX solidos, de la qual calonia sia la meytat del sennor de Albeta o daquel qui por tiempo la terra e la otra meytat por los iusanos que perdran el agua, es a saber, pora Magallon e pora Alberyt e pora Burueta.

Item encara, que sy, por / ventura, el agua de la dita çequia de Marbadon caye en otra cequia e por ally va a la Uecha, que el alcayt de Albeta qui por tiempo sera que de obra de saber tanto quanto el podra aquella agua qui la yto a perdiçion dentro terçer dia que el requerido sera. E sy saber lo puede aquel qui la yto, quel coste de calonia de dia $\mathrm{V}^{\mathrm{o}}$ solidos e de nueyt / LX solidos, la qual dita calonia, si sy (sic) aviniere, sea partida segunt que de suso dito y es. E sy, por ventura, saber no lo puedo quien la yto a perdiçion, que el que jure sobre el Lyvro e la cruz e los Santos Evangelios que el que a dado obra quanto el a podido de saber qui yto aquella agua a perdiçion e que no lo a podido saber por / ninguna cosa.

Item encara, quanto a lo al del feyto del agua que va en vez desde el primer dia de abril daqui a San Johan, qui quiere que regara con el agua sy non quando le caya su vez, que finque la tala en su vertut, segunt que costumpne y es.

E yo, dita dona Taresa Goncalvez de Vera, sennora de Albeta, e yo don Juçe d'Almalhahç e yo don / Mahoma d'Almalhahç e yo Audalla d'Avencantar e yo don Cayt de'Almilluel, nos e toda el aljama de los moros de Albeta, atorgamos e laudamos e confirmamos e aprobamos todas e cadaunas condiçiones en esta carta de conposiçion fecha entre nos e vos, sobreditos don Pero Garçia e don Johan Perz d'Alvos, cavallero, e don D[oming]o de Justa e / Franquo Perz de Cimorra e don Guyllem d'Engans, procuradores del conçello de Magallon, e con vos, don Pero Vere e don D[oming]o Allyas, procuradores del conçello de Alberyt, e con vos, don Pedro Don Yennego, procurador del conçello de Burueta, segunt que en el dita carta de las composiciones mas plenerament y es contenido.

E a mayor firmeça e seguri/dat de todas las avanditas cosas nos, sobreditos don Pero Garçia, clerigo, e don Johan Perez d'Alvos, cavallero, e don D[oming]o de Justa e Franquo Perz de Cimorra e don Guyllem d'Engans, procuradores del conçello de Magallon, e nos, ditos don Pero Vera e don Domingo Alyas, procuradores del conçello de Alberyt, e yo, sobredito don Pedro Don Yennego, procurarador del conçello de Burueta, / e nos, sobreditos dona Taresa Gonçalvez de Vera, sennora de Albeta, e yo don Juçe d'Almalhahç e don Mahoma d'Almalhahç e Audalla d'Avecantar e don Cayt d'Almilluel e toda el aljama de los moros del sobredito lugar de Albeta, nos sobreditos todos ensemble, prometemos e convenimos tener e observar e catar todas e cadaunas condiçiones / en esta carta contenidas.

E qualquiere de nos e de los concellos de los sobreditos logares que las ditas condiciones crebantaran, que de e peyte mil moravedis doro e de dreyto peso o la valor de aquellos, la qual dita pena de los ditos mil moravedis doro pague aquel o aquellos que las sobreditas cosas no aterra ni observara a los / otros que observaran e cataran todas las ditas condiçiones, segunt que de la part de suso mas plenerament son contenidas.

E a pagar la dita pena e atener e conplir todas e cadaunas condiciones de la part de suso ditas obligamos todos nuestros bienes e de los ditos conçellos e aljama mobles e seyentes, ganados o por ganar en cada lo/gar, doquiere que los ayamos.

Testimonios desto son presentes Fertun de Vera e don Johan Perz de Guenbe, cavalleros, veçinos de Borja, e don Johan Gualart, vicario de Magallon, e don Roy Perz, veçino del dito logar de Magallon, e Pero Lopez d'Ondiano e don Pero Bidal, veçinos de Burueta, e don Migual de Mallen, justicia de Alberyt, e Miguel / Perz de Noviellas, veçino del dito logar de Alberyt, e 
Pero Xemenez de Ricla, alcayde de Albeta, e Martin Xemenez de Rada, escudero de la dita dona Taresa Gonçalvez, e don Çalema el Mayorquin e Çalema de Galy, moros, veçinos de Albeta.

Feyta carta dia martes XXI dia (sic) andados del mes de abril era milesima $\mathrm{CCC}^{\mathrm{a}} / \mathrm{XL}^{\mathrm{a}} \mathrm{VIII}^{\mathrm{a}}$.

Sig(signo)no de mi Ferrant Lopez de Raçaçol, notario publico de Borja, que esta carta escrevi e por letras la parti.

1320, junio, 18. Zaragoza.

Jaime II, rey de Aragón, ratifica una orden dada por el Justicia de Aragón a los vecinos de Borja para que paralizaran la construcción de una acequia mediante la cual desviaban el agua hacia sus propiedades e impedían el tránsito de ésta hacia Magallón y otras poblaciones de aguas abajo.

AMM. Copia inserta en documento de 2 de abril de 1322. Escritura gótica semicursiva aragonesa.

Iacobus, Dei gratia rex Aragonum, Valencie, Sardinie et Corsice, comesque Barchinone ac Sancte Romane ecclesie vexillarius, amirantus / et capitaneus generalis fidelibus suis iustitie, iuratis et universis hominibus concilii Burgie, salutem et gratiam.

Ex parte hominum concilii de Magallon et aliorum locorum ripparie rivi de Burgia coram nobis extitit propositum / conquerendo quod vos aperuistis seu incepistis aperire quandam cequiam in magnum dampnum et preiudicium eorundem, sic quod si dicta cequia perficeretur vene quorundam fontium ex quibus vos et ipsi rigatis vestras hereditates abscinderentur et / aqua discurreret ad ipsam cequiam quam aperire incepistis et flueret ad terminum vestrum quem de novo ex ipsa aqua rigare intenditis, de quaquidem apertione cequie fuit mota questio per homines dicti loci de Magallon et aliorum locorum / dicte riparie coram iustitia Aragonum.

Quiquidem iustitia, ad vitandum expensas partium et labores et que talia de plano consueverunt expediri, misit duos bonos hoimnes expertos in ponderatione aquarum et cequiarum ut ipsi viderent / an dicta cequia aperiretur in preiudicium hominum locorum dicte ripparie. Et ipsi homines, visa dicta cequia et ipsis fontibus et cequiis antiquis per quas fluit aqua ipsorum fontium, dixerunt per sacramentum per eos prestitum in posse/ dicti iustitie quod dicta cequia aperiebatur in magnum preiudicium dicte ripparie et quod si perficeretur dicta cequia vene dictorum fontium, quorum fontium alter vocatur de Bargas et alter de Caçuelas, fluerent ad ipsam cequiam et sic / dictus iustitia Aragonum inibuit vobis quod cessaretis a dicto opere quousque nos essemus in regno Aragonum.

Et nos, certifficati (sic) de premissis per dictum iustitiam qui nobis relationem fecit de predictis, vobis dicimus et mandamus quatinus / cessetis ab opere dicte cequie et ipsam in statum pristinum reducatis cum fieret in magnum preiudicium hominum ripparie antedicte.

Aliter, supraiunctario Tirasone vel eius locum tenenti per presentes dicimus et mandamus quod ad predicta vos / forciet et compellat.

Datum Cesarauguste, XIIII ${ }^{\circ}$ kalendas iulii anno Domini millesimo trecentesimo vicesimo.

Vidit S. 
El regadío en Magallón (Zaragoza) hasta el siglo xv y la documentación medieval sobre agua...

4.

1385, abril, 18. Gerona.

Pedro IV, rey de Aragón, perdona a la villa de Borja cualesquiera sanciones impuestas por su primogénito Juan, por el justicia de Aragón, por el castellán de Amposta o por sus oficiales en los pleitos que los borjanos mantenían con sus vecinos, entre los cuales se encontraban sus enfrentamientos con Magallón, Bureta, Alberite y Albeta por el regadio, y prohíbe el establecimiento de penas en contra de Borja.

Archivo Municipal de Borja (AMB), doc. PL3-0011. Pergamino. Escritura gótica bastarda aragonesa. Sello pendiente perdido, aunque se conserva parte del lemnisco.

Nos Petrus, Dei gratia rex Aragonum, Valencie, Maiorice, Sardinie et Corsice, comesque Barchinone, Rossilionis et Ceritanie, prospicientes quod vos, fideles nostri, iurati, probi homines, universitas et singulares persone ville de Burgia, nostrum zelantes servitium / et honorem tanquam boni legales et fideles et naturales subditi et vassalli quam plurima et diversa damna sustulistis universaliter et particulariter pro servicio nostro e rei publice regni Aragonum, intra quod dicta villa est situata et quod propterea meremini a nobis / consequi favores et gratias opportunas, ideo, volentes vos respectu predictorum pro nunc gratiam facere infrascriptam, tenore presentis remittimus, difinimus et relaxamus gratiose et liberaliter vobis, dictis iuratis et probis hominibus ac universitati et singularibus / personis dicte ville, tam christianis quam iudeis quam etiam sarracenis et cuilibet insolidum omnes et singulas penas peccuniarias et etiam corporales que pro parte castellani Emposte vel iuratorum et proborum hominum ac universitatum vel singularium (sic) personarum locorum / de Fuent de Exalon et de Anyon, que sunt dicti castellani et castellanie Emposte, occasione britarum que fuerunt inter vos et illos ex dictis locis super contentione terminorum vel pignorum aut aliter.

Necnon, pro parte parte iuratorum, proborum hominum et uni/versitatum vel singularium personarum locorum de Magallon, de Berueta, de Alverit et de Alveta et aliorum quoruncumque vel illorum quorum sunt dicta loca qui vobiscum litigarunt diutius et litigant pro et super aqua et cequiis rivi vocati «de la Huetxa» et fontium / de Malexan occasione dirutionum faciarum per vos de dictis cequis vel partibus earum contra inhibitiones factas per dictum iustitiam dicti regni vel etiam per nos necnon pro parte fisci nostri vel incliti infantis Iohannis, primogeniti nostri carissimi ac in regnis et / terris nostris gubernatoris generalis contra vos universaliter vel particulariter extiterint aut sint proposite vel accusate vel possent proponi vel accusari pro predictis coram dicto iustitia vel alio quocumque officiali nostro vel dicti nostri primogeniti ordinario vel extra/ordinario aut etiam coram nobis vel dicto nostro primogenito quomodocumque, ita quod sive dicte pene accusate fuerint sive non et sive illas accusari contigerit vel contingat sive non et sive illas incurreritis sive non et sive super illis pro quibus illas / poteritis aut possetis incurri et condempnari inquisitum vel in aliquo processum extiterit sive non.

Et sive in vel pro illis condempnati fueritis vel condempnari possetis vel poteritis sive non et sive accusate fuerint sive non, nunquam pro illis possitis / in iudicio vel extra modo aliquo conveniri nec ad solvendum illas compelli quin potius sitis ab illis et a quacumque illarum penitus quiti et absoluti dum mors aut mutilatio membrorum non extiterint subsequte vobis tamen facientibus civiliter / dumtaxat querelantibus de vobis iustitie complementum coram iudice competente et solventibus dictis officialibus nostris expensas per ipsos factas siquas fecerunt in prosequtione iustitie petite contra vos super predictis. 
Et super dictis penis et accu/satione ac exactione illarum imponimus fisco nostro et dictus nostrus primogenitus silentium perpetuum, mandantes cum hac eadem de certa scientia dicto nostro primogenito et generali gubernatori ac iustitie dicti regni necnon universis / et singulis officialibus et subditis nostris et nostri primogeniti supradicti quatenus huiusmodi remissionem, difinitionem, relaxationem et absolutionem nostras dum et in quantum nobis et fisco nostro pertineant firmas habeant, teneant et observent incon/cusse et contra eas non veniant nec faciant modo aliquo sive forma faciendi quoque contrarium abdicimus eis et cuilibet eorum omnimodam potestatem, mandantes insuper prout supra dictis officialibus quod, visa presenti, cancellent vel can/cellari faciant et nos ad cautelam pro cancellatis haberi volumus et decernimus omnes et singulas inquisitiones contra vos vel aliquem ex vobis factas et manuleutas et obligationes per vos prestitas super premissis qualitercumque, in cuius rei testimonium / hanc vobis fieri iussimus nostro sigillo pendenti munitam.

Data Gerunde, decima octava die aprilis anno a Nativitate Domini millesimo trecentesimo octuagesimo quinto, regnique nostri quinquagesimo.

R[aimundus], canciller.

1407, mayo, 20. Magallón.

El concejo de Alberite reclama treinta y seis bestias de ganado que les habían confiscado los de Magallón, al haberlos acusado éstos de haber permitido el derrumbamiento de un azud en Alberite, expresando los magalloneros su voluntad de retenerlos hasta que los alberitanos repararan dicho azud.

AMM. Original. Pergamino que contiene además otros documentos sobre lo mismo. Escritura gótica aragonesa del siglo XV. Buen estado de conservación, salvo por una rotura en el centro que afecta a cinco líneas.

Anno a Nativitate Domini millesimo quadringentesimo septimo, dia viernes que se contava a vint dias del mes / de mayo, en el puent de la cequia clamada de Pont de Vado, cequia e puent sitiados en termino de la / villa de Magallon, present mi, notario, e los testimonios infrascriptos presentes, en presencia de Ximen Perez de / Ayerbe, arrendador por el castellan d'Anposta de las rentas del lugar d'Anbel, e de Gonbalt de Lihori, / scuderos, habitantes en el lugar de Mallen, fueron personalment constituydos Blas Frances, procurador del / concello e universidat de la villa de Magallon con carta publica de procuracion feyta en la dita villa de Ma/gallon a gueyto dias de noviembre anno a Nativitate Domini millesimo quadringentesimo sexto por el notario / infrascripto; Rodrigo Borau, jurado por los infancones; Johan Bidal, Johan Lavrador, Domingo de Prat, Per / Aznarez de Moncayo, Pero la Ferrera, jurados por los honbres de condicion del annyo present de la dita villa, / los quales verbo dixieron e propusieron el dito procurador en el nonbre qui de suso e los ditos jurados, / en nonbre e voz del dito concello e universidat de la dita villa de Magallon, que como cierto fuesse / e notorio que toda ora o vegada que el açut de Magallon, sitiado en el termino del lugar / de Alberit, por fuerca de aguas o de gentes darmas de la tierra o estrangeras o por fuerca o / flumen de aguas o ignorantment o cientment o en qualquiere otra manera el dito açut de / Magallon e la cequia dalli avant decurrient la agua de aquel e de aquella daqui a las Gamellas / se distillara, se perdra o del todo se perdra o crebara; que los honbres del concello e universidat del lugar / d'Alberit, requeridos por el concello e universidat de la dita villa de Magallon, son tenidos decentment / de levantar e reparar el dito 
acut e cequia daqui a las Gamellas a costas et misiones suyas e satisfer et / emendar a los honbres del concello e universidat de la dita villa de Magallon toda aquella agua e los dannyos / e menoscabos que por razon del dito crebamiento, derruimiento, perdimiento o distillamiento de la dita agua / que del dito acut e cequia se havra distillado, colado o perdido e se havran seguido a los honbres / de la dita universidat de la dita villa de Magallon.

E como agora nuevament el dito acut / de Magallon sia crebado, el agua discurra en partida la Guega a yuso e no vienga toda por la dita / cequia de Magallon enta las Gamellas e los honbres del concello e universidat de la villa de Magallon / sian e son en uso, dreyto, costunbre e possesion de pendrar e fer pendras en los honbres del concello / del lugar d'Alberit en las puertas del lugar d'Alberit o dentro del dito lugar o en el mont et / terminos de la dita villa de Magallon o en el mont e terminos del dito lugar d'Alberit o doquiere / que los honbres e concello e universidat de la dita villa de Magallon trobaran los bestiares o ganados grosos / o menudos del dito lugar d'Alberit e traer e adozir las ditas pennyoras dentro en la dita villa de / Magallon sines penas, miedos, temores e calonias algunas del senyor rey d'Aragon e justicia d'Aragon, governa/dor d'Aragon ni de otro nengun jutge ecclesiastico o seglar e aquellas tener dentro en la dita villa tanto / e tan largament daqui a que los honbres e concello del lugar d'Alberit los ditos acut e cequia de la dita villa / de Magallon adobados reparados $<$ havran $>$, de manera que pont ni poca ni partida de agua no se discurra / por los ditos açut e cequia asi mesmo daqui a tanto que los honbres del concello del dito lugar d'Alberit / havran satisfeyto, pagado e emendado a los honbres e concello e universidat de la dita villa de Magallon / todos los dapnages e menoscabos que havran havido e sostenido por el dito perdimiento o distilla/miento de la dita acut e cequia de Magallon, los quales dannyos e menoscabos an astimar ( $\mathrm{sic}$ ) e son en / uso, dreyto, costumbre e possesion de estimarlos el justicia e los jurados e honbres del concello e universidat / de la dita villa de Magallon.

Et como por el dito perdimiento o distillamiento de la dita agua el dito pro/curador e los ditos jurados con partida dotros honbres de la dita villa de Magallon ayamos penyo/rado trenta e seys bestias de diversos pelos e naturas de los honbres del dito lugar d'Alberit se/gunt que evidentment aquello de mi, dito e infrascripto notario, e de los ditos e infrascriptos testimonios / e de los ditos Eximen Perez d'Ayerbe, arrendador sobredito, e de Gonbalt de Lihori, scuderos, los quales dapnages / e menoscabos los sobreditos procurador e jurados con los otros honbres de Magallon qui alli presentes / eran estimoron (sic) de mil solidos a suso e de dos mil solidos a yuso daqui a la otra que se havian seguido en lures / miesses, arboles, linos, canyamos, malluelos, t [ermin]os e vinnyas que por occasion del dito crebamiento / o distillamiento de la dita agua de los ditos [acut] e cequia protestando de los dannyos e menoscabos ad/venideros, los quales les finq(roto)ensas por la dita razon feytas e fazederas.

Encara protestoron / encara protestoron (sic) e protiestan (roto) dreyto, uso, costumbre e possesion a los honbres del concello e universi/dat de la dita villa de [Magallon] que han sobrel dito pendrar e sobre los ditos acut e cequia e sobre / el agua por los ditos acut e cequia decurrient, de las quales cosas requeridas e protestadas requirieron / a mi, notario infrascripto, que carta publica testimonial les ne testificase, una / o muytas, tantas quantas neçesarias [seran], la qual o las quales se dixieron dar mas largament / ordenadas.

Et yo, infrascripto notario, ofrecieme perellado fer aquello qui deviesse de mi officio.

Presentes / testimonios fueron a las sobreditas cosas Martin de Moncon, menor de dias, e Johan Martin Lazar, / alyas de Luna, vezinos de la dita villa de Magallon. 
Sig(signo)no de mi Johan Perez de Roviz, habitant en la villa de Magallon et por / actoridat del sennyor rey notario publico por todo el regno d'Aragon, / qui a las sobreditas cosas present fue et aquesto scrivie con sobrescrip/to e emendado en la XXXII linea do se lie «havra» e cerre.

6.

1459, mayo, 27. Alberite de San Juan.

El concejo de Alberite vende a Magallón los derechos a construir en sus términos una acequia para el riego de sus montes y de los términos comunales por el precio de quinientos cincuenta sueldos jaqueses, que reciben con la aliara y bajo ciertas condiciones.

AMM. Original. Pergamino. Escritura gótica aragonesa del siglo XV. Buen estado de conservación, salvo por alguna pequeña rotura.

Sia a todos manifiesto que clamado, convocado o ajustado el concello e universsidat del lugar de Alberit dentro la eglesia de Senyora Santa Maria del dito lugar do e segunt que otras vegadas el dito conce/llo es usado e acostunbrado plegar e ajustarsse pora tales e senblantes actos fazer, de mandamiento de los justicia e jurados del dito lugar dius scriptos, por voz, siquiere publico pregon, de Johan de $\mathrm{Ca} /$ stro, corredor publico del dito lugar segunt quel dito corredor fizo fe et relacion a mi Martin de la Ferrica, notario dius scripto, presentes los testimonios infrascriptos et de mandamiento de los justicia e jurados del dito lugar infrascriptos haver clamado publicament el dito concello por los luguares ( lugar de Alberit pora los dia, lugar et negocio dius scriptos, en el qual concello intervinieron et fueron presentes congregados e ajustados / nos Sancho d'Alfaro, lugartenient de justicia; Garcia de Jacca, Anthon Gil, Johan Frances, menor, Ferrando Paules, jurados; mosen Sancho Mallen, clerigo, Gonçalbo Quintana, scudero, Pero Bonel, Johan Blasco, Pero Mallen, Pascual / del Villar, Martin Paules, Pero d'Alfaro, Domingo de Jacca, Pascual Esthevan, scudero, Johan de Castro, joven, Johan de Jacca, Anthon Frances, Miguel Martinez, Johan Matut, Blasco Martinez, Miguel Blasco, Miguel de Vera, Johan / Martin, Pero Gil, vezinos et habitadores del dito lugar de Alberit, <et desi todo el concello del dito lugar de Alberit>, concellantes, concello fazientes, celebrantes et repressentantes, todos concordes et alguno de nos no discrepant ni contradizient, de nostras sciertas sciencias / e agradables voluntades, et certeficados plenerament de todo nuestro dreyto et de todo el dreyto del dito concello et universidat del dito lugar de Alberit et de los singulares de aquel, por nosotros et por los nuestros et por el / dito concello et universidat del dito lugar de Alberit et por los singulares de aquel, presentes, absentes e advenideros, vendemos et lugo ( $\mathrm{sic}$ ) de present livramos, asignamos et atorgamos al concello et universidat de la villa / de Magallon suelo, siquere passo, en et por los terminos nuestros, siquiere de nos, sobredito concello et universidat del dito lugar de Alberit, assi por los terminos distintos et determinados nuestros como por los terminos que son comunes / entre nos, dito concello, et el sobredito concello de Magallon pora la cequia quel dito concello de Magallon abre, saqua et faze por levar l'agua que passa dius el puent clamado «el puent del rio», termino del dito lu/gar de Alberit pora regar los montes de la dita villa de Magallon, a saber es, por aquella partida de los ditos nuestros terminos et encara de los ditos terminos comunes que al dito concello de Magallon plazan et bien vista sera.

Et por / quanto de present el d[ito concell]o de [Magall]on ha principiado de (tomar?) [siquiere ronper] et abrir la dita cequia (ilegible) demosle licencia et facultat si querra [qu]e la pueda mudar, ronper e abrir et tomar mas alta por nuestros terminos alla / do et por do le plaze- 
El regadío en Magallón (Zaragoza) hasta el siglo xv y la documentación medieval sobre agua...

ra una vegada tan solament con tal empero condicion quel dito concello de Magallon pague et satisfagua (sic) el danyo que se fara en las hered[ades] que se romperan abriendo la dita cequia a los seny(roto) aquellas, el qual / danyo haya et sia primero stimado por dos personas, una por part nuestra et otra por part del dito concello de Magallon diputaderas.

Et encara mas quel dito c[once]llo de Magallon sia tenido fazer et faga canales de riego la una vega/da en todos los bracales antigos que abriendo la dita cequia se ronperan por forma que por aquellos pueda [pa]ssar et passe liberament l'agua de los ditos bracales.

Otrosi, es condicion que los honbres de la dita villa de Magallon hayan / passo libre por los oriellos de la dita cequia et que puedan echar en nuestros terminos, a saber es, en las fronteras de la dita cequia la esconbra, siquiere enrruna, que daquella saquaran sin pena alguna, pagando empero el danyo que en las / heredades faran.

El qual dito suelo et passo de cequia vendemos et atorgamos, segunt dito es, al dito concello de Magallon con las condiciones o facultat sobreditas salvament, franquo, libero et quito de cens, tributo et de toda otra carga / de servitut et sines de alienacion, obligacion et voz mala por precio, es a saber, de cincientos e cinquanta solidos dineros jaqueses, buena moneda corrible en el regno de Aragon, los quales contantes atorgamos haver havido et en poder / nuestro recebido ensenble con el aliaria ( $\mathrm{sic}$ ), renunçiantes a toda excepcion de frau et denganyo et de no haver havido et contantes en poder nuestro recebido los ditos cincientos e cinquanta solidos, precio de la dita vendicion ensenble con el aliara / porque queremos et expresament consentimos quel dito suelo et passo de cequia que vendemos desta ora en adelant el dito concello de Magallon haya, tenga, possida et spleyte plenament, franqua, segura et en paz pora dar, / vender e enpenyar, camiar, feriar, permutar et encara pora passar et levar liberament por aquel, siquiere por la cequia nueva quen ( $\mathrm{sic}$ ) aquel abrira et fara la sobredita agua a los montes de la dita villa de Magallon pora reguar ( $\mathrm{sic}$ ) aquellos / con la dita agua et pora fazer del dito suelo, siquiere passo, et cequia nueva quen aquel se abrira et encara de la sobredita agua que por aquella yra et passara a todas sus proprias voluntades como de cosa suya propria, segunt que mil/lor, mas sanament et proveytosa todo lo sobredito et dius scripto puede seyer dito, scripto, cogitado et entendido a pro, salvamiento et buen entendimiento del dito concello de Magallon, toda contrariedat nuestra et del dito con/cello de Magallon, toda contrariedat nuestra et del dito concello de Alberit et de los singulares de aquel et de toda otra persona cessant.

Empero la present vendicion fazemos et atorgamos sin prejudicio ni lession alguna de una sentencia arbitral dada entre / nos, sobredito concello de Alberit, et el dito concello de Magallon et reconoxemos et atorguamos ( sic) que nos, sobredito concello de Alberit, ni los singulares de aquel no hemos ni han adenprivio ni dreyto alguno de regar con la dita agua por / la dita cequia nueva; antes aquella toda entregament yndo ( sic) et passando por la dita cequia nueva es del dito concello de Magallon, salva enpero la part del precio de la dita agua que se bendra a nos, dito concello de Alberit, / pertenexient por vigor de la dita sentencia arbitral.

Et prometemos et nos obligamos nos, sobreditos justicia, jurados, concello et universidat del dito lugar de Alberit, vendedores, al dito concello et universidat de la dita villa de / Magallon o a qui el querra et mandara fer haver, tener, possedir et spleytar perpetualment a todos tiempos el dito suelo, siquiere passo, de cequia quen vendemos salvament, franqua, segura et en paz, sines pleyto ni contra/dicion alguna, et seyer ende tenidos et obligados de plenaria eviccion, guarentia et defenssion contra todas et qualesquiere personas de qualquier ley, estado o condicion sian pleyto, question, enbargo o mala voz en aquel / inponientes en qualquier manera con las condiciones et salvedat sobreditas. 
Et si, lo que Dios no mande, pleyto, question, enbargo o mala voz sera puesto o movido en tiempo alguno al dito concello de Magallon o a los suyos / en et sobrel dito passo, siquiere suelo, de cequia que le bendemos por qualesquiere persona o personas de qualquiere ley, estado o condicion sian, prometemos et nos obligamos enpararnos del dito pleyto, question, enbargo et mala / voz et deffender al dito concello de Magallon de aquel et levar aquel a proprias missiones et spensas nuestras, del principio del pleyto daqui a la fin de aquel entro a que por sentencia diffinitiva passada en cossa judgada, de la qual / no pueda seyer apellado, suplicado ni de nullidat o, puesto, sia savido et determinado et el dito concello de Magallon romanga, finque et sia en pacifica possession del dito suelo et paso de cequia que le bendemos et / aquesto tantas vegadas quantas acahecera seyer puesto o movido pleyto, question, enbargo o mala voz en el dito suelo et passo de cequia que bendemos.

Et si contecera, lo que Dios no mande, nos ditos vendedores seyer ven/cidos de los di<tos> pleytos, questiones, enbargos o malas vozes o de alguno dellos por do al dito concello de Magallon convenisse perder o lexar el dito suelo et passo de cequia que le bendemos, prometemos et nos obligamos resti/tuyr et tornarle el sobredito precio que del hemos havido et en poder nuestro recebido et satisfer, pagar et emendarle qualesquiere expensas, danyos et menoscabos que feyto et sustenido havra por la dita razon en qualquiere / manera, de los quales et de las quales queremos et expresament consentimos quel dito concello de Magallon sia creydo por su sinple palabra sines testimonios, jura et toda otra manera de probacion.

Et a todas et cada / unas cosas sobreditas tener et conplir nos, ditos vendedores, obligamos todos nuestros bienes et todos los bienes et rendas del sobredito concello et universidat del dito lugar de Alberit mobles / mobles ( sic) et sedientes, havidos et por haver en todo lugar.

Et encara prometemos, convenimos et nos obligamos de haver, dar et asignar bienes nuestros et del dito concello et universidat del dito lugar de Alberit et de los singulares de aquel proprios, quitos et desenbargados a complimiento de todas et cada unas cosas sobreditas, las quales queremos et expresament consentimos que puedan seyer et sian sacados de nuestras casas et de cada uno de nos et de qualquier otro / lugar que trobados seran et vendidos sumariament a uso et costunbre de cort et de alfarda, feytas de aquellos tres almonedas por tres dias, toda otra solempnidat et subastacion foral cessant.

Et renunciamos a dia de a/querdo et diez dias pora cartas cerquar et a todas et cada unas otras excepciones et dilaciones de Fuero et de Dreyto a las sobreditas cosas et cada una dellas repugnantes, siquiere contradizientes.

Feyto fue aquesto en / el dito lugar de Alberit, a vint e siet dias del mes de mayo anno a Nativitate Domini millesimo quadringentesimo quinquagesimo nono.

Presentes testimonios fueron a las sobreditas cosas don Ximeno Sanchez Breton, cleri/go, habitant en el dito lugar de Alberit, et Johan Pastriz, molinero, habitant en la ciudat de Boria.

Sig(signo)no de mi Martin de la Ferrica, habitat (sic) en la ciudad de Boria et, por auctoridat real, notario publico por toda la tierra et senyoria del serenissimo senyor rey de Aragon, qui a las sobreditas cosas presente fui et aquellas screvi / et screvir fiç consta de sobrepuestos et de rasos correctos en las lineas $\mathrm{VII}^{\mathrm{a}}$ do es scripto «et desi todo el concello del dito lugar de Albe-

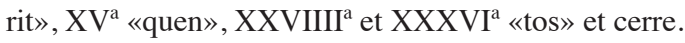


El regadío en Magallón (Zaragoza) hasta el siglo xv y la documentación medieval sobre agua..

\section{Referencias bibliográficas}

AGUILERA, I. (2009), «La "Fuente del Ojo" en Albeta: Aqua sacra de época flavia», Cuadernos de Estudios Borjanos, LII, pp. 13-27.

ANDREU, J. (1999), «Las comarcas de Borja y del Moncayo en época celtibérica», Cuadernos de Estudios Borjanos, XLI-XLII, pp. 111-238.

BARCELÓ, M. (1989), «El diseño de espacios irrigados en Al-Andalus: un enunciado de principios generales», en L. Cara (ed.), El agua en zonas áridas. Arqueología e historia. Hidráulica tradicional de la provincia de Almería, Almería, Instituto de Estudios Almerienses, pp. XV-L.

BELTRÁN, F. (2006a), «An irrigation decree from Roman Spain: The Lex Rivi Hiberiensis», Journal of roman studies, 96, pp. 147-197.

- (2006b), «La epigrafía romana sobre el agua en la cuenca media del Ebro. El Bronce de Agón», en Aquaria. Agua, territorio y paisaje en Aragón, Zaragoza, Gobierno de Aragón y Diputación Provincial de Zaragoza, pp. 87-93.

BOLEA, J. (1986), Los riegos de Aragón, Huesca, Grupo Parlamentario Aragonés Regionalista de las Cortes de Aragón.

CABANES, M. ${ }^{a}$ D. (1987), «Los mudéjares de Muzalcoraz y el monasterio de Veruela: datos de una economía del siglo XII», en IV Simposio Internacional de Mudejarismo: Economía, Teruel, Centro de Estudios Mudéjares, pp. 143-149.

- (en prensa), Documentos del monasterio de Santa María de Veruela (Zaragoza), Zaragoza, Anubar.

CARRANZA, G. (2009), La Huecha y la elma. Una historia de riegos y conflictos en el valle del río Huecha, Borja, Centro de Estudios Borjanos.

DEL VAL, M. ${ }^{a}$ I. y BONACHÍA, J. A. (eds.) (2012), Agua y sociedad en la Edad Media hispana, Granada, Universidad.

FALCÓN, M. a I. (2010), «La ciudad de Borja y la villa de Magallón en el siglo XV según documentos de la Cancillería Real del Archivo de la Corona de Aragón», Cuadernos de Estudios Borjanos, LIII, pp. 69-158.

FRAGO, J.A. (1980a), Toponimia del Campo de Borja. Estudio lexicológico, Zaragoza, Institución «Fernando el Católico».

- (1980b), «Observaciones filológicas sobre una carta notarial del año 1243», Analecta Malacitana, III, pp. 401-414.

GARCÍA, E. (1960), Las comarcas de Borja y Tarazona y el somontano del Moncayo. Estudio geográfico, Zaragoza, Instituto «Juan Sebastián Elcano» e Institución «Fernando el Católico».

GERRARD, Ch. (2011), «Contest and co-operation: strategies for medieval and later irrigation along the upper Huecha valley, Aragón, north-east Spain», Water History, 3, pp. 3-28.

GONZÁLEZ,A. (1945), «Notas sobre el régimen de riegos en la región de Veruela en los siglos XII y XIII», Al-Andalus, X, pp. 79-88. 
HEREZA, J. I. (coord.) (2001), La presa de Almonacid de la Cuba: del mundo romano a la Ilustración en la cuenca del río Aguasvivas, Madrid, Doce Calles.

KIVIHARJU, J. (1989), Los documentos latino-romances del monasterio de Veruela 1157-1301: edición, estudio morfosintáctico y vocabulario, Helsinki, Suomalainen Tiedeakatemia.

LAJUSTICIA, J. (2003), Agón, Agón, Ayuntamiento.

LALIENA, C. (2008), «Agua y progreso social en Aragón, siglos XII-XVIII», en ¿Agua pasada? Regadíos en el Archivo Histórico Provincial de Zaragoza, Zaragoza, Gobierno de Aragón, pp. 53-84.

- (2009), «Hidráulica mudéjar en una sociedad feudal. Infraestructura, producción y renta en el regadío musulmán del valle del Ebro en los siglos XII y XIII», XI Simposio Internacional de Mudejarismo, Teruel, Centro de Estudios Mudéjares, pp. 279-304.

- y ORTEGA, J. (2005), Arqueología y poblamiento. La cuenca del río Martín en los siglos V-VIII, Zaragoza, Grupo «CEMA» y Gobierno de Aragón.

LIAUZU, J. G (1964), «Un aspect de la reconquête de la vallée de l'Ebre aux XIe et XIIe siècles. L'agriculture irriguée et l'heritage de l'Islam», Hespéris-Tamuda, V, pp. 5-13.

LOSTAL, J. (1980), Arqueología del Aragón romano, Zaragoza, Institución «Fernando el Católico».

MADANI, T. (2012) L’hydraulique dans le monde musulman médiéval, Helsinki, Academia Scientiarum Fennica.

MARTÍNEZ, M. (2010), La cultura del agua en la Murcia medieval (ss. IX-XV), Murcia, Universidad y Centro de Estudios Históricos e Investigaciones locales «Región de Murcia».

Ordenanzas (1993): Ordenanzas de la Comunidad de Regantes de la villa de Magallón, Borja, Imprenta Sancho.

ORTEGA, J. y LALIENA, C. (2012), «Formas feudales de especulación agraria: villas, viñas y acequias en el sur de Aragón (ca. 1170-1240)», en J. Torró y E. Guinot (eds.), Hidráulica agraria y sociedad feudal. Prácticas, técnicas, espacios, Valencia, Universitat, pp. 79-102.

PANADERO, C. (1991), «La Arcadia feliz. Los regadíos islámicos. Introducción», en Historia de los regadíos en España (...a. C.- 1931), Madrid, Ministerio de Agricultura, Pesca y Alimentación.

PARDOS, E. (1973), Magallón. Apuntes históricos de la villa y tierra, Soria, Urbión.

RODRÍGUEZ, F. S. (2009), «Pleitos entre Magallón y Mazalcoraz por cuestiones de riego en los siglos XIV y XV», Aragón en la Edad Media, XXI, pp. 221-224.

- (2010), El dominio del monasterio cisterciense de Santa María de Veruela desde su fundación hasta 1400, Zaragoza, Institución «Fernando el Católico».

- (2011), Historia del regadío en los dominios de la casa ducal de Híjar, Zaragoza, Institución «Fernando el Católico». 
El regadío en Magallón (Zaragoza) hasta el siglo xv y la documentación medieval sobre agua...

RÚJULA, P. y LAFOZ, H. (1995), Historia de Borja. La formación histórica de una ciudad, Borja, Ayuntamiento.

SABIO, A. (ed.) (en prensa), Medievo, tiempos modernos, contemporaneidad. La villa de Magallón, siglos XII-XX, Zaragoza, Diputación Provincial y Ayuntamiento de Magallón.

SARASA, E. (1989), «La memoria del agua: la economía hidráulica en el valle medio del Ebro. ¿Un ejemplo de supervivencia o de nueva implantación tras la conquista cristiana en el siglo XII?», Aragón en la Edad Media, 8, pp. 635-636.

- (2008), «La economía hidráulica en el valle medio del Ebro: de la explotación islámica a la cristiana», en M. ${ }^{a}$ I. Del Val y O. Villanueva (coords.) Musulmanes y cristianos frente al agua en las ciudades medievales, Santander, PUbliCan y Ediciones de la Universidad de Castilla-La Mancha, pp. 155-172.

SESMA, J. A.; UTRILLA, J. F. y LALIENA, C. (2001), Agua y paisaje social en el Aragón medieval. Los regadíos del río Aguasvivas en la Edad Media, Zaragoza, Ministerio de Medio Ambiente y Confederación Hidrográfica del Ebro.

TEIXEIRA, S. (1995), El dominio del monasterio de Veruela: la gestión de un espacio agrario andalusí, Barcelona, Universitat Autónoma [tesis doctoral en microficha].

URIBE, P.; FANLO, J.; MAGALLÓN, M.a A.; BEA, M.; MARTÍNEZ, R.; REKLAITYTE, I. y LAMBÁN, F. (2011), «La presa romana de Muel: novedades de hidráulica romana en el valle del Ebro», en L. G. Lagóstena, J. L. Cañizar y L. Pons (eds.), Aquam perducendam curavit. Captación, uso y administración del agua en las ciudades de la Bética y el occidente romano, Cádiz, Universidad, pp. 333-345.

UTRILLA, J. F. (1996), «Aprovechamiento hidráulico, distribución del agua y conflictos sociales en el valle medio del Ebro: el ejemplo del río Aguasvivas (siglos XII-XV)», en Tecnología y sociedad: las grandes obras públicas en la Europa medieval. XXII Semana de Estudios Medievales. Estella 1995, Pamplona, Gobierno de Navarra.

VV. AA. (2010), La fuente de la vida: usos e imágenes del agua en la Edad Media, La Laguna, Servicio de Publicaciones de la Universidad. 
Francisco Saulo Rodríguez Lajusticia

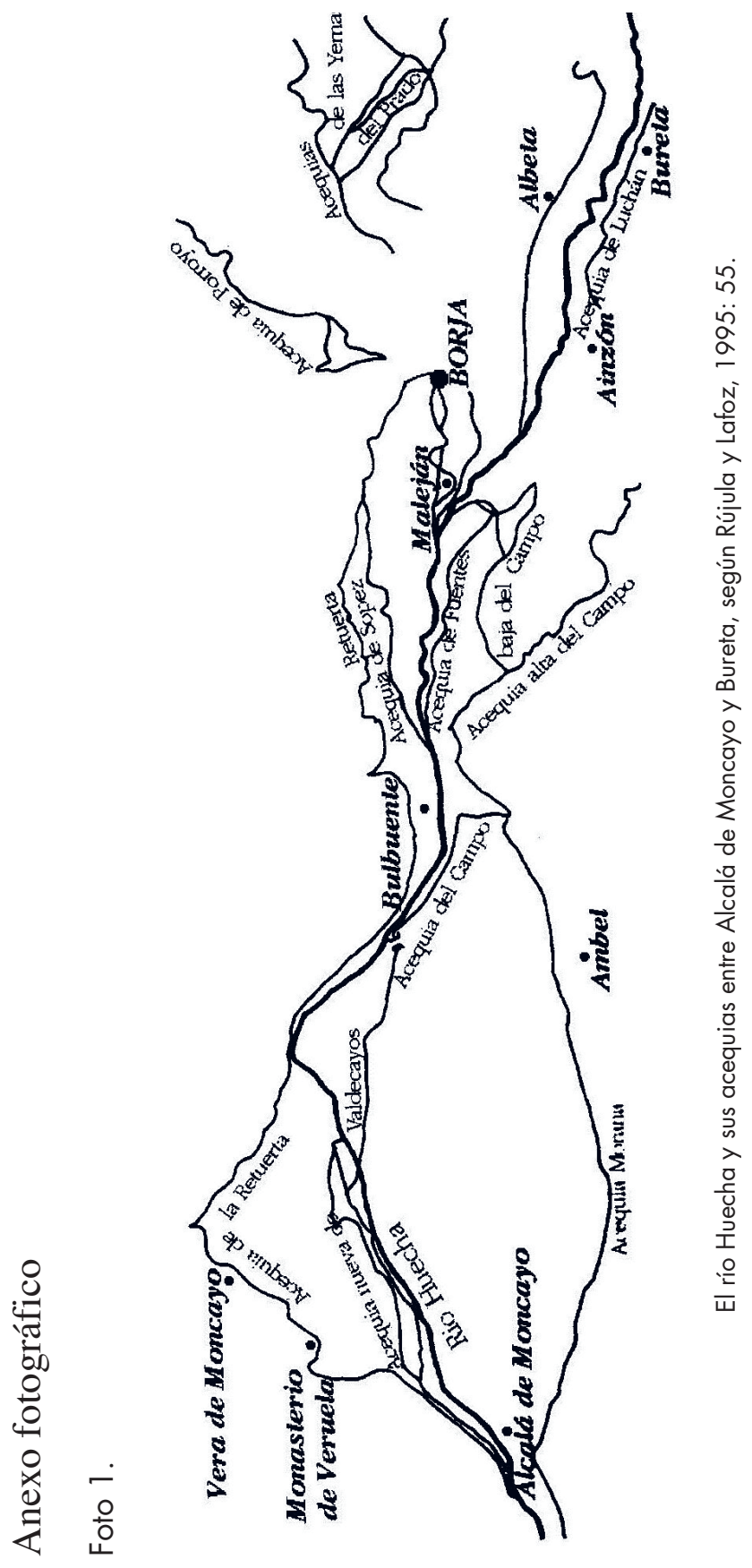




\section{Foto 2.}

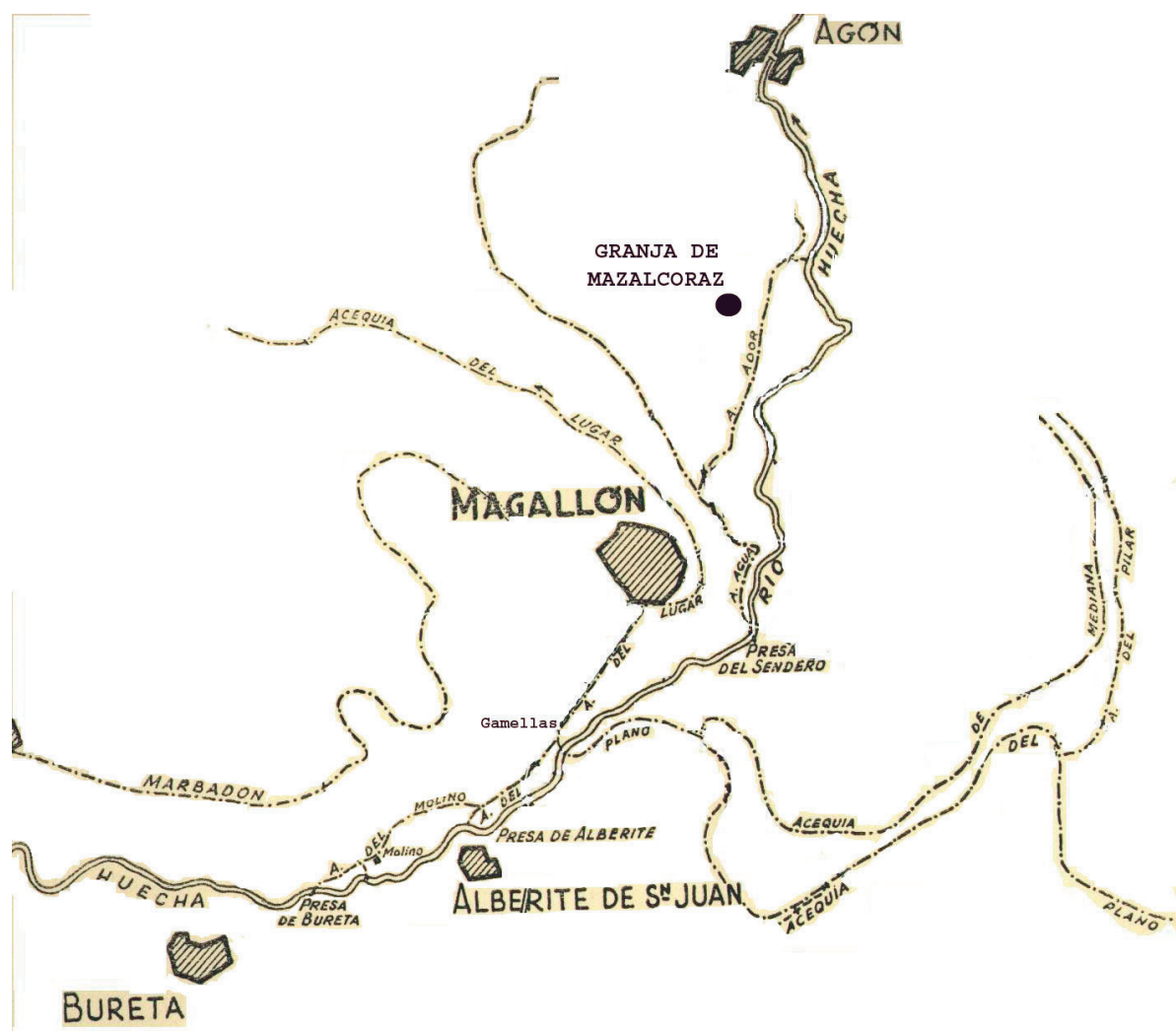

El regadío en las inmediaciones de Magallón, según García, 1960: 88. 
Francisco Saulo Rodríguez Lajusticia

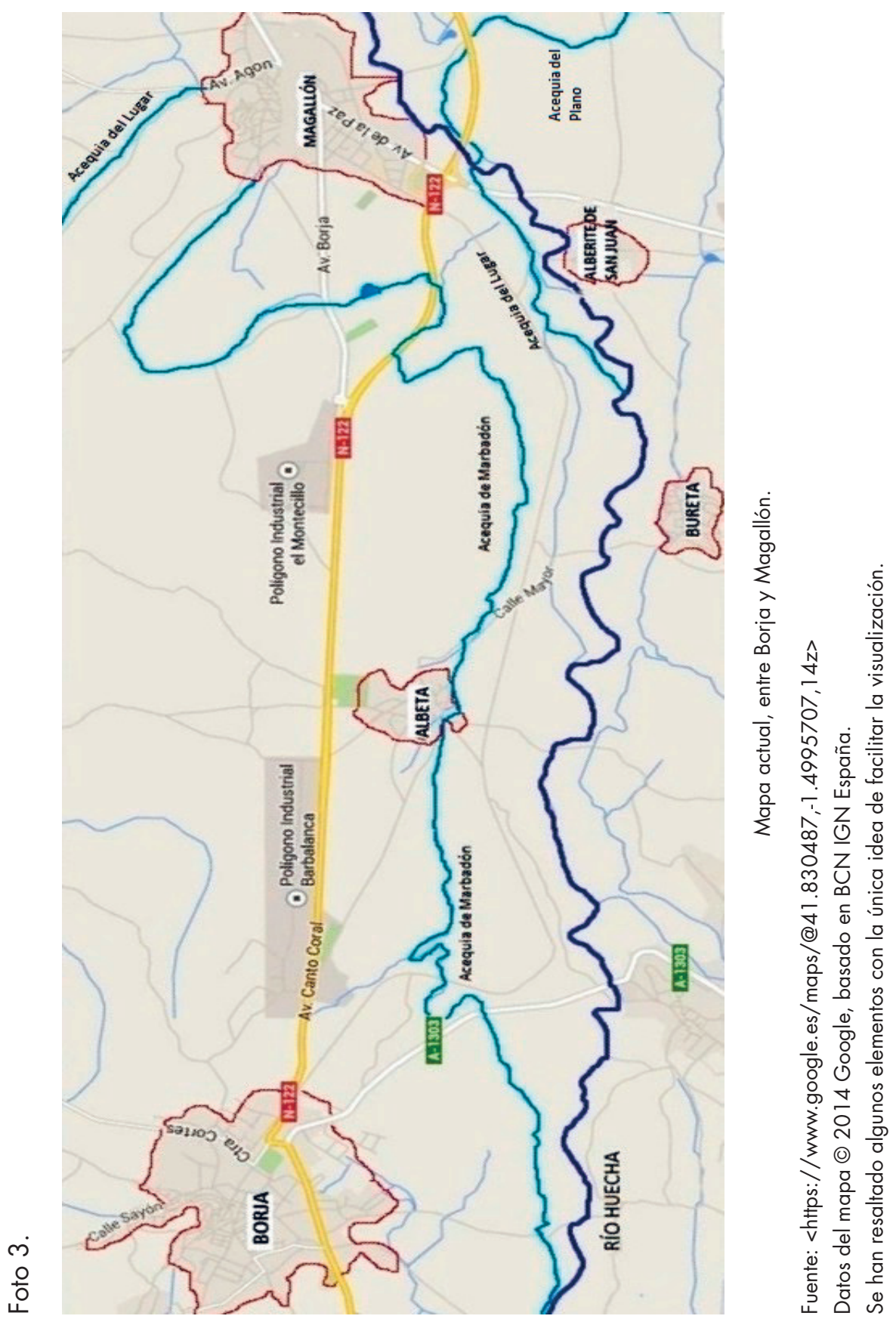

